\title{
Did the Eruption of the Mt. Pinatubo Volcano Affect Cirrus Properties?
}

\author{
Zhengzhao Luo \\ Department of Earth and Environmental Science \\ Columbia University \\ New York, NY 10027 \\ William B. Rossow \\ NASA Goddard Institute for Space Studies \\ New York, NY 10025 \\ Toshiro Inoue \\ Meteorological Research Institute, 1-1 Nagamine, \\ Tsukuba, Ibaraki 305, Japan \\ Claudia J. Stubenrauch \\ Laboratorie de Météorologie Dynamique du CNRS, \\ Ecole Polytechnique, \\ Palaiseau, France
}

August 30, 2001

Submitted to Journal of Climate

Corresponding authour address: Zhengzhao Luo 2880 Broadway, Room 608

New York, NY 10025

Email: johnny@tempest.giss.nasa.gov 


\begin{abstract}
Some observations suggest that the volcanic aerosols produced by the Mt. Pinatubo eruption may have altered cirrus properties. We look for evidence that such modification of cirrus is extensive enough to be climatically significant by comparing three satellite-based cirrus datasets produced by the ISCCP analysis, the "split-window" analysis, and 3I analysis. Since the former two have not been compared in detail before, we conduct such a comparison here. When applied to AVHRR data, both the ISCCP and split-window analyses identify about $0.2-0.3$ cirrus cloud amount in tropical latitudes; however, there are detailed differences of classification for about half of these clouds. The discrepancies are attributed to the simplified assumptions made by both methods. The latter two datasets are derived from infrared radiances, so they are much less sensitive to volcanic aerosols than the ISCCP analysis. After the Mt. Pinatubo eruption, the ISCCP results indicate a dramatic decrease of thin cirrus (cloud top pressure $<440 \mathrm{mb}$ and visible optical thickness $<1.3$ ) over ocean, accompanied by a comparable increase of altocumulus and cumulus clouds; over land, there are no significant changes. In contrast, results from the splitwindow and $3 \mathrm{I}$ analyses show little change in thin cirrus amount over either ocean or land that is associated with the volcanic eruption. The ISCCP results can, therefore, be understood as a misclassification of thin cirrus because the additional reflected sunlight by the volcanic aerosol makes the cirrus clouds appear to be optically thicker. Examination of the split-window signature and the infrared emissivities from 3I show no significant change in infrared emissivity (or optical thickness). These results indicate that the Mt. Pinatubo volcanic aerosol did not have a significant systematic effect on tropical cirrus properties, but rather produced only temporary, local effects. Hence, these results indicate that there was no significant climate feedback produced by aerosolcirrus-radiative interactions.
\end{abstract}




\section{Introduction}

Cirrus clouds are high-level (upper troposphere), optically thin, ice clouds with both low solar reflectivities and low emissivities (Liou 1986). Globally, they cover around $20 \%$ of the earth's surface (Rossow and Schiffer 1999), but there may be another 5 $10 \%$ of very thin cirrus present (Jin et al. 1996; Liao et al. 1995; Stubenrauch et al. 1999a). Unlike most other clouds, cirrus with cloud tops higher than the effective emission level of the clear atmosphere cause net radiative heating of the earth-atmosphere system because they reflect sunlight less than they decrease the outgoing longwave radiation. This warming effect is reversed as cirrus cloud optical thickness increases (Stephen et al. 1990). Through their radiative effects cirrus clouds modulate the general circulation of the atmosphere (Randall et al. 1989; Ramanathan et al. 1983).

There are many ways to observe cirrus properties and behavior; however, only satellites provide the global overview of cloud systems at the scale of the synoptic weather systems in which they form (Rossow 1989). The past two decades have witnessed numerous studies of cirrus clouds using satellite instruments. Inoue (1985) showed the feasibility of cirrus detection using the "split-window" data (wavelengths around $11 \mu \mathrm{m}$ and $12 \mu \mathrm{m}$ ) of the Advanced Very High Resolution Radiometer (AVHRR) on board NOAA-7 and derived the temperature and the emissivity of cirrus clouds. Furthermore, based on a threshold technique in two-dimensional brightness temperature histograms, he developed a method that could be used to identify several types of clouds (Inoue 1987). ISCCP was established in 1982 to produce a globally uniform satellite cloud climatology (Schiffer and Rossow 1983; Rossow and Schiffer 1991). In the second version of the cloud product, sensitivity to cirrus is increased and biases in cirrus 
cloud optical thickness and cloud top temperature are reduced (Rossow and Schiffer 1999). Wylie et al. (1994) applied the $\mathrm{CO}_{2}$ slicing technique, which makes use of infrared radiances at wavelengths from 13 to $15 \mu \mathrm{m}$ from the High Resolution Infrared Sounder (HIRS) data from NOAA polar-orbiting satellites, to derive four years of high cloud climatology. Their new study extends the climatology to eight years (Wylie and Menzel 1999). More recently, Stubenrauch et al. (1999 b) developed a new improved initialization inversion (3I) algorithm and used it to convert TIROS-N Operational Vertical Sounder (TOVS) observations from NOAA polar-orbiting environmental satellites into atmospheric temperature and water vapor profiles, as well as cloud and surface properties. Cirrus clouds are separated from high opaque clouds by their lower emissivities.

Volcanic activities may alter cirrus properties. Jensen and Toon (1992) suggested the potential effect of volcanic aerosols on cirrus cloud microphysics using simulations, while Sassen et al. $(1992,1995)$ proposed a volcano-cirrus-climate feedback mechanism based on analysis of data from the First ISCCP Regional Experiment (FIRE). Moreover, Song et al. (1996) examined the interannual variability of high-level cloudiness (HC) index and found a widespread increase of the $\mathrm{HC}$ index up to 0.1 after major volcanoes. However, ISCCP results suggest that the production of large amount of stratospheric aerosol by Mt. Pinatubo is associated with a decrease in cirrus cloud amount by $0.02-$ 0.04 and an increase in their average optical thickness (Rossow and Schiffer 1999). How exactly did Mt. Pinatubo volcano affect cirrus properties? We explore this question by comparing the ISCCP products with two other cloud datasets derived from the "splitwindow" method and 3I cloud algorithm (Stubenrauch et al. 1999b). 
In the first half of the paper, we report a systematic comparison between cirrus retrieved by ISCCP and the split-window method. This comparison study serves as a preparation for the second half of the paper, which addresses how Mt. Pinatubo eruption affected cirrus properties. First, a radiative transfer model is used to analyze the two algorithms, because the split-window method is based on the identification of clusters in multidimensional radiance space, while the ISCCP cloud scheme relies on a radiative transfer model to retrieve cloud properties. Second, retrieved cloud information is compared in light of the model simulation results. Cirrus from the 3I cloud dataset have been compared to those from ISCCP by Stubenrauch et al. (1999a).

In the second half of the paper, we make use of the different sensitivities of the three cloud retrieval algorithms to explore the influence of the Mt. Pinatubo volcano on cirrus properties. One major difference between the split-window method, 3I cloud algorithm, and the ISCCP cloud scheme is that the former two use radiances at infrared wavelengths, while the latter utilizes one infrared and one visible radiance. Since absorption in the infrared is less sensitive to aerosols than reflection in the visible, the split-window method and 3I cloud algorithm do a better job of monitoring thin cirrus even when stratospheric aerosol concentration is relatively high, such as after a large volcanic eruption. The ISCCP cloud scheme, which depends on visible reflectance to derive cloud optical thickness, could attribute the additional visible reflectance caused by aerosols to clouds, thus introducing errors in the cloud retrieval (Rossow and Schiffer 1999). Hence, there may be artifacts in the changes of ISCCP retrieved cirrus after Mt. Pinatubo volcano, whereas cirrus retrieved by the split-window method and 3I cloud algorithm are less likely to be affected by the event. 
This paper is divided into five sections. Section 2 gives a short description of the datasets and cloud retrieval techniques used in the study. Section 3 presents a comparison of the split-window and ISCCP cloud algorithms, using both simulations and observations. In section 4, cloud datasets from ISCCP, split-window method, and 3I are examined to find out the influence of the Mt. Pinatubo eruption on cirrus properties. Section 5 summarizes the main findings.

\section{Data and Analysis Methodologies}

\section{a. AVHRR datasets and split-window method}

Channel $4(\approx 11 \mu \mathrm{m})$ and channel $5(\approx 12 \mu \mathrm{m})$ data from AVHRR on NOAA-7 were used by Inoue $(1987 ; 1989)$ to implement his "split-window" method. In this paper, we continue to use AVHRR data (sampled and saved in ISCCP DX products) from NOAA11 for the period from January 1989 to December 1993, covering both the pre- and posteruption period (Mt. Pinatubo volcano erupted in June 1991). AVHRR also has two solar channels (wavelengths of $0.6 \mu \mathrm{m}$ and $0.7 \mu \mathrm{m}$, respectively) and one near infrared channel (wavelength of $3.7 \mu \mathrm{m}$ ). The spatial resolution of the global AVHRR product is $4.0 \mathrm{~km}$ and the imaging frequency is twice daily at lower latitudes. To save data volume, the ISCCP data is spatially sampled to intervals of approximately $30 \mathrm{~km}$ (Schiffer and Rossow 1985).

Inoue (1985) has shown that cirrus clouds can be identified by inspection of the images constructed from the brightness temperature difference (BTD) measured at $11 \mu \mathrm{m}$ 
and $12 \mu \mathrm{m}$. In his following papers, Inoue proposed an objective cloud type classification method based on a threshold technique in a two-dimensional histogram (Inoue 1987; 1989). Following Inoue (1989), we call this method the split-window method, in which cloud types are classified by the brightness temperature (TBB) at 11 $\mu \mathrm{m}$ and the BTD $(11 \mu \mathrm{m}$ minus $12 \mu \mathrm{m})$ as in Figure 1a. TBB is used to separate highlevel clouds from low-level clouds, while BTD is a good indicator for distinguishing between optically thick and optically thin clouds. In this paper, we modify the original classification thresholds of the split-window method in such a way as to facilitate the comparison with ISCCP data and to take advantage of more information. For example, cloudy or clear in the new version of the split-window method is decided based on the ISCCP cloud/clear decision. Accordingly, the clear BTD is calculated wherever ISCCP sees clear conditions. This is justified because our main interest is in the comparison of cirrus retrieved by the two cloud schemes and also because the original split-window method utilizes a much simpler threshold test to separate cloudy scenes from clear ones than does ISCCP. Another main modification is that the threshold for high-level clouds is changed from a constant $\operatorname{TBB}\left(-20^{\circ} \mathrm{C}\right.$ in Figure la) to a variable TBB corresponding to a constant cloud top pressure, namely $440 \mathrm{mb}$ (the average temperature at this level in the tropics and mid-latitudes ranges from about $-15^{\circ} \mathrm{C}$ to $-25^{\circ} \mathrm{C}$ ). This is consistent with the cloud classification in the ISCCP cloud scheme (see section $2 b$ ). The modified version of cloud classification of the split-window method is shown in Figure 1b.

\section{b. ISCCP method}

ISCCP collects and analyzes infrared $(\approx 11 \mu \mathrm{m})$ and visible $(\approx 0.6 \mu \mathrm{m})$ radiances measured by the imaging instruments on all the operational weather satellites. In this 
paper, we only consider the results from NOAA-11 AVHRR. ISCCP cloud analysis procedure consists of three principal steps: cloud detection, radiative model analysis, and statistical analysis (Rossow and Schiffer 1991). Cloud detection is achieved in two passes through the whole dataset (Rossow and Garder 1993). First, a series of spatial and temporal tests are performed to estimate clear values of visible and infrared radiances for each field-of-view (FOV); second, the whole radiance dataset is examined again and each radiance is compared with the corresponding clear value. If either the infrared radiance is smaller than the clear value by more than some threshold amount or the visible radiance is larger than the clear value by more than some threshold amount, the pixel is labeled cloudy. After pixels are classified as clear and cloudy, the measured radiances are compared to radiative transfer model calculations to retrieve cloud top temperature (Tc) and visible optical thickness (Tau) for cloudy pixels, and surface reflectance and surface temperature for clear pixels. Clouds are represented in the radiative model as a single, thin layer, uniformly covering the image pixel with a specified average particle size and size distribution. When cloud optical thickness is small enough (as for thin cirrus), such that a significant portion of radiation from the surface and atmosphere below is transmitted, the retrieved value of $\mathrm{Tc}$ is reevaluated to account for this transmission. For clouds colder than $260 \mathrm{~K}$, the cloud microphysical model is an ice cloud composed of 30 $\mu \mathrm{m}$ polycrystals (Rossow and Schiffer 1999).

Clouds are classified in ISCCP according to cloud-top pressure ( $\mathrm{Pc}$ ) and optical thickness (Figure 2). In section 3, simulations employing a radiative transfer model will be used to relate the ISCCP cloud scheme and the split-window method.

\section{c. 3 I cloud scheme and dataset}


The Improved Initialization Inversion (3I) procedure is a physical-statistical algorithm for retrieving atmospheric temperature and water vapor profiles as well as cloud and surface properties from TOVS observations, using HIRS and Microwave Sounding Unit (MSU) (Chédin et al. 1985). The original 3I cloud scheme was based on a combination of the " $\mathrm{CO}_{2}$ slicing" method and the "coherence-of-effective-cloud-amount" method, using channels within the $\mathrm{CO}_{2}$ absorption band around $14 \mu \mathrm{m}$ (Wahiche et al. 1986, Stubenrauch et al. 1996). Comparison with ISCCP led to an improved 3I cloud retrieval scheme based on a weighted- $\chi^{2}$ method which estimates the coherence of effective cloud amount at different pressure levels. The introduction of weights taking account of temperature profile uncertainty yields unbiased cloud parameters at all cloud heights for

homogeneous cloud types (Stubenrauch et al. 1999b). 3I cloud properties (cloud-top pressure Pc and effective cloud amount $\mathrm{N} \varepsilon_{\mathrm{cld}}$ ) are determined from averaged radiances over all cloudy pixels within each $100 \mathrm{~km}$ by $100 \mathrm{~km}$ box, assuming a single, homogeneous cloud layer. Cirrus are defined as cloud with $\mathrm{Pc}<440 \mathrm{mb}$ and $\mathrm{N} \varepsilon_{\mathrm{cld}}<0.9$.

Cirrus from the 3I cloud dataset have been compared with those from ISCCP by Stubenrauch et al. (1999a). Results show that 3 I identifies $10 \%$ more cirrus than ISCCP DX over mid- and low latitude ocean; over tropical land, the difference is $20 \%$. These discrepancies can be explained in part by the different detection sensitivities for their cirrus (c.f. Liao et al. 1995 and Jin et al. 1996) and in part by small-scale horizontal and vertical heterogeneities to which the two datasets respond differently due to differences in spatial and spectral resolutions (Stubenrauch et al. 1999c).

\section{Comparison of Cloud Retrieval Techniques and Observations}


We present a comparison of the split-window and ISCCP results, since this has not been done before; a detailed comparison of 3I and ISCCP is given in Stubenrauch et al. $(1999 a ; 1999 c)$.

The split-window method is based on the identification of clusters in a twodimensional brightness temperature histogram of TBB and BTD. The ISCCP cloud analysis relies on a radiative model to retrieve cloud-top pressure $(\mathrm{Pc})$ and cloud optical thickness (Tau) explicitly for each pixel and then uses these properties for a cloud classification. Therefore, a radiative transfer model, Streamer (Key 1996), is used as a bridge to compare these two cloud classifications.

\section{a. Radiative transfer model description}

Streamer (version 2.5p) is used to simulate AVHRR split-window channel radiances under clear and different cloudy conditions. Streamer can be used for computing either radiances (intensities) or irradiances (fluxes) for any viewing geometry in 24 shortwave and 105 longwave bands under a wide variety of atmospheric and surface conditions (Key 1996). A discrete ordinate solver (Stamnes et al. 1988) is used to compute radiances. Four absorbing gases are considered: water vapor, carbon dioxide, ozone, and oxygen. Seven standard atmospheric profiles are built-in but any other profile can be specified. Cloud optical properties are based on three different parameterization schemes: water cloud scheme ( $\mathrm{Hu}$ and Stamnes 1993), ice cloud shortwave scheme (Fu and Liou 1993), and ice cloud longwave scheme (parameterized single scattering properties of ice spheres using Mie theory). Aerosol amounts can be distributed vertically either by a user-supplied profile or one of the internal standard profiles. In Streamer, "each computation is done for a scene, where the scene can be a mixture of up to 10 
cloud types occurring individually, up to 10 overlapping cloud sets of up to 10 clouds each, and the clear sky, all over some combination of up to three surface types" (Key 1996).

Streamer's accuracy in clear-sky conditions has been tested by comparing computations to other models in the Intercomparison of Radiation Codes in Climate Models (ICRCCM) (Ellingson et al. 1991). In all five standard cases, ranging from tropical to subarctic winter atmosphere, the longwave fluxes computed by Streamer were within $5 \%$ and one standard deviation of the mean of all the models (Jin and Rossow 1997). Pinto et al. (1997) compared the Streamer's modeled downwelling broadband longwave irradiance with that of the observation and found a bias of $3 \mathrm{~W} / \mathrm{m}^{2}$.

\section{b. Comparison of cloud retrieval techniques}

AVHRR radiances from split-window channels are simulated using Streamer for clear and different types of clouds represented by their Pc and Tau values, consistent with the ISCCP cloud classification (see Fig 2). Microphysical properties such as cloud particle effective radius ( $10 \mu \mathrm{m}$ for water clouds and $30 \mu \mathrm{m}$ for ice clouds) and water content are specified to be the same as in the ISCCP retrieval model. Since the split-window method makes no explicit assumptions about the microphysics (with one exception noted below), we choose this approach to focus solely on cloud classification differences.

Figure 3 and 4 show a series of simulations of BTD as a function of cloud-top pressure (Pc) and optical thickness (Tau) for the Air Force Geophysical Laboratories (AFGL) reference tropical profile (McClatchey et al. 1971). Besides Pc and Tau, BTD is also sensitive to cloud phase, cloud particle size distribution, and a few other microphysical properties (Wu 1987; Parol et al. 1991; Giraud et al. 2001). Replacing the single 
scattering properties of ice spheres by those of ice polycrystals (Mitchell et al. 1996) in these calculations (not shown) decreases the BTD by about $0.5 \mathrm{~K}$, but the structure of the figure stays the same. The upper panels of the two figures assume all clouds are composed of ice particles, while the middle panels assume all clouds are water clouds. The lower panels combine these two cases so that clouds above $440 \mathrm{mb}$ level are ice and clouds below that are liquid. The simulations are done for two different satellite zenith angles covering the extremes for AVHRR.

Generally, these simulations show that cirrus clouds, which are at high altitude and optically thin, have larger BTD values compared with other types of clouds and clear sky (BTD is not zero for clear sky because of the spectral dependence of water vapor absorption; see Figure 5). However, there is one unexpected feature: besides thin cirrus, a second local maximum of BTD exists where PC is around $500 \mathrm{mb}$ and TAU is about 1.3, depending on satellite zenith angle. This second maximum is caused by two competing effects that combine to determine the BTD values. On the one hand, water clouds have larger BTD values than ice clouds (see Fig 3 and 4), because BTD tends to be larger for clouds with smaller particle size (Wu 1987; Giraud et al. 2001). On the other hand, BTD also exhibits a larger value for higher and optically thinner clouds, because these clouds (such as cirrus) generate a larger difference in emissivity between the two split-window channels (Inoue 1985). For these reasons, cirrus clouds have larger BTD because they are high and optically thin, while thin liquid altocumulus clouds also have relatively large BTD because they consist of small particles and are also high and thin enough. Thus, there is potential for confusion between the thinnest midlevel water clouds and higher-level ice clouds. 
In addition to BTD, TBB has also been simulated as a function of Pc and Tau (not shown). Based on the two cloud classification schemes (Fig 1 and Fig 2) and the simulations of BTD and TBB, we find out the link between the two cloud classifications: Figure 6 shows how clouds classified by ISCCP are categorized by the split-window method, depending on satellite zenith angle. For example, at nadir thin cirrus seen by the split-window method corresponds to almost all the cirrus seen by ISCCP, plus some cirrostratus, midlevel clouds and very thin low clouds. Thick and dense cirrus defined by the split-window method almost all fall into the cirrostratus category defined by ISCCP. However, as satellite zenith angle increases, the two methods agree better on cirrus. Therefore, Figure 6 provides the basis for comparing cirrus retrieved by ISCCP and the split-window methods in the next subsection.

\section{c. Comparison of retrieved cloud information}

For each pixel in the ISCCP DX dataset, the clear-sky TBB and BTD, and cloudy/clear decision already inferred by the analysis are used by the split-window method to retrieve clouds from the cloudy-sky radiances. We compare the two cloud retrieval techniques by showing cloud type frequency distributions of each cloud type classified by one technique as a function of the classification by the other. The resulting table is like a two-dimensional probability density function. Five years of data have been processed: results are similar for all years. We show the tables derived from two regions where cirrus clouds prevail: warm pool ocean (western Pacific) and African tropical land (see Table 1 and Table 2). Numbers in the tables represent the cloud amount (CA) frequency distribution. 
In the warm pool area, both methods identify about 20 to 30 percent cirrus; however, they do not agree exactly on which clouds are cirrus. More than half of the cirrus clouds identified by the split-window method are called cirrus by ISCCP and the rest are distributed between mid-level and low-level thin clouds. A similar distribution is obtained, when surface observations are used to identify cirrus for corresponding ISCCP scenes (Hahn et al. 2001). Likewise, more than three fourths of cirrus identified by ISCCP are called cirrus by the split-window method, but some are classified as other clouds such as $\mathrm{N}$-type (partial cloud cover, non-black low-level clouds, and low-level black clouds overlaid by thin cirrus) and cumulonimbus clouds by the split-window method. Over African tropical land, similar results are found, except that both method find less cirrus there than in the warm pool ocean.

The radiative model studies in the previous part have shown that the cirrus defined by the split-window method may include some optically thin, liquid, mid-level clouds. ISCCP also retrieves cloud-top temperatures that are too large when cirrus overlies lower-level clouds, thus mistakenly labeling some cirrus as altocumulus (Jin et al. 1996; Stubenrauch et al. 1999c). It is hard to tell which effect dominates based only on the data we have. Further work is needed to separate clouds that are falsely detected as altocumulus by ISCCP from those that are real altocumulus. One possible way might be to make use of collocated radiance data at other wavelengths, such as the $6.7 \mu \mathrm{m}$ water vapor band, to check the signature of real cirrus, since radiances at $6.7 \mu \mathrm{m}$ saturate for midlevel clouds but are still sensitive to cirrus.

\section{Application to the Mt. Pinatubo case}


We make use of the differences of the several cloud retrieval algorithms to find out whether the Mt. Pinatubo volcano affected cirrus.

In the ISCCP analysis, the $0.6 \mu \mathrm{m}$ visible channel, which is important in determining cloud optical thickness, is also sensitive to the scattering by atmospheric aerosols, especially when their optical thickness is larger than normal like following the Mt. Pinatubo eruption. However, aerosol effects are not included in the ISCCP radiative model. Therefore, they will affect the analysis of clouds (Rossow et al. 1996). This effect is negligible in normal conditions when the optical thickness of stratospheric aerosol is of order $10^{-2}$. However, after the large volcanic eruption of Mt. Pinatubo in June 1991, the situation was very different. By late 1991 the stratospheric aerosol optical thickness (at $0.5 \mu \mathrm{m}$ wavelength) determined from SAGE II over the equatorial region was around 0.2 or larger, while the value inferred from AVHRR was as large as 0.45 (Stenchikov et al. 1998). An optical thickness of 0.2 is already large enough to affect the retrieval of thin cirrus in the ISCCP analysis as we show later. The split-window method, on the other hand, is not easily affected by stratospheric aerosols since it utilizes the radiances from two much longer infrared wavelengths, which are not scattered effectively by the very small stratospheric particles. We also examine the 3I cloud data, which, like the splitwindow method, utilizes only IR radiances for cloud property retrieval (there is one cloud test out of eight during daytime that uses visible radiances).

\section{a. "Pinatubo-Cirrus" story and one apparent discrepancy}

Jensen et al. (1992) studied the possibility that volcanic aerosols may significantly alter the concentration of ice crystals which nucleate in cirrus and assessed the potential impact of these processes on the evolution and radiative properties of cirrus. Their model 
simulations suggest that under certain conditions the effect on cirrus of volcanic sulfate aerosols transported down into the upper troposphere could be to increase the concentration of ice crystals by as much as a factor of 5 and increase the surface warming of certain types of cirrus near the tropopause by as much as $8 \mathrm{~W} / \mathrm{m}^{2}$. Nevertheless, Jensen et al. (1994) found that cirrus properties are generally much less sensitive to the number of condensation nuclei $(\mathrm{CN})$ present than to other factors such as temperature, cooling rate, and vertical wind speed.

Sassen et al. $(1992,1995)$ studied a jet stream cirrus case during the FIRE II Intensive Field Observations (IFO) and suggested that Pinatubo aerosols might be influencing the cirrus properties. The field observations were carried out in south Kansas on 5 and 6 December 1991 during a period of moist subtropical flow when a strong jet stream swept cirrus clouds through the area. Observed tropopause folding was believed to be the mechanism for injecting stratospheric aerosols of volcanic origin into the troposphere. Unusual cirrus cloud microphysical properties, such as "abnormally high ice crystal concentration, perhaps unique radial ice crystal shapes, and relatively large haze particles in cirrus uncinus", suggested the alteration of cirrus by contamination from decaying volcanic debris within six months of the Mt. Pinatubo volcano (Sassen et al. 1995). They also pointed out the possible climatic implications. Although the Mt. Pinatubo aerosol is estimated to have cooled the earth's surface temperature by less than $1{ }^{\circ} \mathrm{C}$ by direct reflection of incoming solar radiation, the additional effects of perturbed cirrus clouds could provide either a competing or reinforcing climatic adjustment in the years following the eruption. 
Wylie and Menzel described a gradual increase of high-level cloud amount in tropics and northern mid-latitudes by about $0.005 /$ yr from 1989 to 1997 . They employed a cloud retrieval technique, called the $\mathrm{CO}_{2}$ slicing method, which is capable of correctly identifying most of transmissive clouds using the HIRS infrared bands with partial $\mathrm{CO}_{2}$ absorption (Wylie et al. 1994). The $\mathrm{CO}_{2}$ slicing technique using the HIRS instrument is more sensitive to the very thin cirrus than ISCCP, finding almost twice as much thin cirrus as the first version of ISCCP (C-series) did (Jin et al. 1996). A study by Stubenrauch et al. (1999a) shows an improvement of cirrus frequencies by $10-20 \%$ from CX to DX due to increased sensitivity to cirrus over land in the DX analysis and a better treatment of ice clouds in the DX radiative model. On the other hand, the $\mathrm{CO}_{2}$ slicing technique is sensitive to surface temperature errors. Positive surface temperature errors cause detection of more thin cirrus. Jin et al. (1996) found that in the old HIRS analysis (Wylie et al. 1994) SST values are about $2 \mathrm{~K}$ warmer than the blended satellite ship values, but its surface temperature is significantly underestimated over high topography causing an under-detection of cirrus.

Figure 7 shows the global changes of cirrus detected by ISCCP during a period of five years: from January 1989 to December 1993. In contrast with Wylie and Sassen's findings, ISCCP sees a decrease in thin cirrus (defined below) cloud amount by $0.02-$ 0.04 globally after the eruption of Mt. Pinatubo. However, the corresponding and opposite change of cumulus cloud amounts shown in the same figure, together with the fact that both changes occur preferentially over oceans, suggests that these changes may be caused by the effect of the aerosol in the satellite visible radiances instead of real changes of the clouds (Rossow and Schiffer 1999). During the same period of time, a 
slight increase in the average optical thickness of cirrus is also found in the ISCCP dataset, which still might be consistent with Sassen and Jensen's studies.

What actually happened to cirrus after the Mt. Pinatubo eruption? To answer this question, we check other satellite observations that are not as sensitive to volcanic aerosols.

\section{b. Most likely scenario for the changes of cirrus properties after Mt. Pinatubo volcano}

Mt. Pinatubo volcano erupted on Luzon Island in Philippines (15.10N, 120.40E), with the strongest explosion on June 15, 1991. Following the June 15 eruption, the evolving cloud of water vapor, sulphurous gases and aerosol spread out both longitudinally and latitudinally and occupied a latitude band of approximately $20 \mathrm{~S}$ to $30 \mathrm{~N}$ within a few months (McCormick et al. 1995). Figure 8 shows the zonal mean total stratospheric aerosol extinction as a function of latitude and time observed from SAGE II (cf. Fig. 3 in Stenchikov et al. 1998). Total stratospheric aerosol extinction at $1.02 \mu \mathrm{m}$ wavelength was about $0.05 / \mathrm{km}$ or even higher in tropical and subtropical regions from one or two months after the volcano to around one and half a year later, which is greater than the pre-eruption level by about a factor of 50. Stenchikov et al. (1998) calculated aerosol optical thickness from these data: at $0.525 \mu \mathrm{m}$ wavelength values exceeded 0.2 .

The influence of the volcanic event on the amounts of various cloud types as seen by ISCCP and the split-window data are shown in Figure 9 and 10. These two figures show the zonal mean cloud amount as a function of latitude and time, starting from the beginning of 1989 to the end of 1993 . To isolate the influence of the volcano, the mean seasonal cycle has been removed from the original data. Similar to the data manipulation in the previous section, each cloudy pixel is processed according to the two cloud 
retrieval methods, and then cloud amount is calculated in a large region by counting the fraction of cloudy pixels. The original ISCCP cirrus cloud classification is further divided into two groups: thin cirrus (Tau $<1.3)$ and thick cirrus $(1.3<$ Tau $<3.6)$. Such division is justified by their different responses to the volcanic eruption as will be shown. Over tropical and subtropical oceans, ISCCP sees a dramatic decrease of thin cirrus clouds after the Mt. Pinatubo eruption, decreasing from a normal value around 0.1 to below 0.02 and not fully recovering until late 1993. Similar changes are not observed for thin cirrus over land. In the ISCCP dataset, there is also a slight increase in thick cirrus over both ocean and land. On the other hand, observations from the split-window analysis do not show any significant changes of thin or thick cirrus associated with the volcanic eruption over either ocean or land.

Since the optically thinnest, high-level clouds are usually detected by the IR threshold, the aerosol will not significantly affect cloud detections (Rossow and Schiffer 1999). However, because the ISCCP radiative model does not include aerosol effects, any additional reflectance caused by aerosols is combined with that by clouds, thus increasing the retrieved cloud optical thickness. In this situation, the thinnest cirrus may be misclassified as some other type. In the ISCCP analysis, the clear-sky visible reflectance over ocean is constrained by a model of ocean surface reflectance, so that the additional visible reflectance caused by volcanic aerosols is included with the clouds; but over land, the clear-sky reflectance is calculated from the data each month, so, the volcanic aerosols increase the land surface visible reflectance and not the clouds (Rossow and Schiffer 1999). Thus, the Pinatubo aerosols increase the ISCCP retrieved average optical thickness of cirrus over ocean as first pointed out by B. Soden (private communication). 
Furthermore, the sub-micron-sized aerosols have a smaller asymmetry parameter, thus they are better reflectors of incoming solar radiation than the larger cirrus particles. As a result, their contributions to the retrieved cloud optical thickness are even greater than their nominal optical thickness values. All these effects are negligible in normal conditions, because the optical thickness of background aerosol is of order $10^{-2}$. But during the Pinatubo event, aerosol layers as thick as 0.2 are comparable to some thin cirrus clouds. In the ISCCP analysis, cloud top pressure is adjusted for optically thin clouds to account for transmitted IR radiation. This adjustment process is very sensitive to the optical thickness value used for the thinnest clouds; indeed, for those cirrus with optical thickness less than 1 , sensitivity tests show that the magnitude of the reflectivity increase by the volcanic aerosol may cause the ISCCP analysis to retrieve cloud top temperature tens of degrees higher. Therefore, the extra visible reflectance added to the thin cirrus cloud layers by the Pinatubo aerosols causes the reassignment of thin cirrus to lower-level cloud types. Figure 9 shows an increase of altocumulus and cumulus clouds in the ISCCP results as expected from this analysis. Moreover, the split-window method, which is not so sensitive to volcanic aerosols, shows little change in thin cirrus amount.

Figure 11 compares the variation of cirrus cloud amount with time from the ISCCP and 3I datasets, covering a few years before and after the Mt. Pinatubo eruption. The observations used in this analysis of the 3I dataset are from NOAA-11 satellite; only daytime observations are shown. Again, seasonal cycles are removed from the original data. Generally, thin cirrus $\left(\mathrm{Pc}<440 \mathrm{mb}\right.$ and $\left.\mathrm{N} \varepsilon_{\mathrm{cld}}<0.5\right)$ and thick cirrus $(\mathrm{Pc}<440 \mathrm{mb}$ and $\left.0.5<N \varepsilon_{\mathrm{cld}}<0.9\right)$ as seen by $3 \mathrm{I}$ do not show any significant changes that are associated with Mt. Pinatubo eruption. There are some changes of cirrus over tropical 
and subtropical land, but they are probably caused by the shifting orbit of NOAA-11, which has a larger effect on cloud sampling over land where the diurnal cycle of clouds may be stronger. 3I cloud datasets should in general not be affected by the volcanic aerosols due to the use of IR radiances; however, there is one cloud test out of eight during daytime that uses visible radiances. Therefore, a small increase about 0.02 of thin cirrus over subtropical and tropical oceans may be attributable to such an effect (Stubenrauch and Eddounia 2001). Thin cirrus as seen by ISCCP decrease dramatically and abruptly in the tropics (up to 0.08 decrease within a few months) and thick cirrus increase gradually after the Mt. Pinatubo volcanic eruption. So, this comparison shows the same contrast in changes of cirrus after Mt. Pinatubo volcano, as in the ISCCP-split window comparison.

In fact, comparing Figure 8 with Figure 9, 10, and 11 provides further support for our interpretation. The aerosol patterns derived from SAGE II and thin cirrus distributions seen by ISCCP are spatially and temporally very similar, with a correlation coefficient as high as -0.85 in the tropics. In contrast, the correlation between the $3 \mathrm{I}$ thin cirrus and the SAGE II aerosol is 0.35 in the same region; the correlation between the thin cirrus identified by the split-window method and the SAGE II is only 0.09 . This appears to be consistent with the relative sensitivities of these methods to aerosols.

Besides coverage, cloud optical thickness is another important cloud property that determines cloud radiative effects. If cirrus cloud amount has not undergone significant changes after the Mt. Pinatubo volcano, their microphysical properties and their optical thickness may still have been affected by volcanic aerosols. Since the optical thickness reported by ISCCP includes the contribution from aerosols, we look at the BTD between 
11 and $12 \mu \mathrm{m}$ as a surrogate. Figure 12 and 13 show the BTD for tropical and subtropical cirrus-like clouds identified by both ISCCP and the split-window method as a function of latitude and time (only tropical and subtropical BTDs are shown because the split-window method works better at lower latitudes than at higher latitudes). Similar to figure 9 and 10, the mean seasonal cycle has been removed from the original data. BTD for clear sky is also shown for comparison in figure 13. Generally, BTDs for cirrus do not change significantly after the Mt. Pinatubo eruption. (Because the ISCCP temperature digitization is about $0.5^{0}$ to $0.8^{0}$ for the temperature range relevant here, any temperature anomaly lower than that is not considered significant.) There is a slight decrease of BTD for the ISCCP identified thick cirrus and cirrostratus, starting in 1992. According to simulations (see Fig. 3 and 4), this may be made possible by increasing cloud top pressure or increasing cloud optical thickness (except for tropopause cirrus). In other words, thick cirrus and cirrostratus may have thickened and moved to lower altitude after Mt. Pinatubo eruption. However, this change is only marginally detectable. Furthermore, since the change starts more than one year after the volcanic event, there may be other reasons for this change than an indirect effect of volcanic aerosols. Therefore, we conclude that Mt. Pinatubo eruption did not have a significant effect on cirrus cloud optical properties over the temporal and spatial scales by which our data are analyzed. However, our results should not be taken as contradictory to those by Sassen (1995) because Sassen et al. looked at changes of cirrus in a particular meteorological event. It is still possible that the Pinatubo aerosols have a local influence on the cirrus, like that observed by Sassen et al., but we did not find any systematic effect on both cirrus amount and cirrus optical properties. 


\section{Summary and Discussion}

In the first half of the paper, we compared cirrus retrieved by ISCCP and the splitwindow method. By using a radiative transfer model, Streamer, a series of simulations have been carried out, showing that cirrus clouds, defined in ISCCP as Pc $<440 \mathrm{mb}$ and Tau $<3.6$, have a large BTD, which is used by the split-window method to isolate cirrus. However, the simulations also show that some thin mid-level clouds with small liquid particles could exhibit BTD values large enough to be included in the thin cirrus category. When applied to AVHRR, both ISCCP and the split-window method identify around 20 to 30 percent cirrus clouds in the tropical oceanic and terrestrial regions; however, there is detailed disagreement in classification for half of these clouds (see Fig. 6). These discrepancies are attributed to the simplifying assumptions made by both methods. For example, the split-window method does not consider water clouds that may show a similar signature as high-level clouds. ISCCP, on the other hand, may retrieve a cloud top temperature that is too large for some cirrus because of small errors in the retrieved optical thickness. Collocated $6.7 \mu \mathrm{m}$ water vapor channel radiances, which are sensitive to high-level clouds, but not to mid-level clouds, would be helpful in resolving some of these discrepancies.

In the second half of the paper, we make use of different sensitivities of several cloud retrieval techniques to find out what actually happened to cirrus after the Mt. Pinatubo volcanic eruption. The datasets taken into consideration are the ISCCP data, the splitwindow observations, and 3I cloud data. Because the latter two datasets are derived from infrared radiances, they are much less sensitive to volcanic aerosols than the ISCCP data 
(although daytime 3I results have some sensitivity to visible reflectivity increase by aerosols). After Mt. Pinatubo eruption, ISCCP detects a dramatic decrease of thin cirrus ( $\mathrm{Pc}<440 \mathrm{mb}$; Tau $<1.3$ ) over ocean by a factor of five compared with their normal amount, accompanied by a comparable increase of altocumulus and cumulus clouds; over land no significant changes of thin cirrus have been observed in ISCCP. On the contrary, results from the split-window observations and 3I data show little change in thin cirrus that is associated with the volcanic eruption over both ocean and land. According to 3I data, there is a slight increase of thin cirrus amount by 0.02 in the subtropics and tropics. Careful examination of ISCCP cloud algorithm suggests that the apparent large decrease of thin cirrus in ISCCP data is probably an artifact due to the additional visible reflection by volcanic aerosols hanging around in the stratosphere (Rossow and Schiffer 1999). This would affect both cloud optical thickness and adjustment of cloud top height; thus, thin cirrus could be classified as other clouds. Over land, the volcanic aerosols just increase land surface visible reflectance (as found). Therefore, the most likely scenario is close to what has been observed by $3 \mathrm{I}$ data and the split-window observations. Besides cirrus cloud coverage, another possible influence on cirrus of Mt. Pinatubo volcano is some alteration of cloud microphysical and optical properties. However, by looking at the changes of the BTD as a surrogate of cloud optical thickness, it is suggested that the Pinatubo aerosols did not systematically and significantly influence cirrus optical properties on the global scale, either. Previous studies showing some changes are probably isolated local effects. Thus, there is no indication in these results of a climatically significant feedback where aerosol-altered cirrus produced an additional climate effect beyond the direct aerosol-radiative effect. 
Acknowledgement. We benefited from conversations with K. Sassen and E. Raschke. J. Jonas and D. Rind provided us with SAGE data. This work is supported by NASA Radiation Science Program (managed by Dr. Don Anderson) and NOAA office of Global Programs Climate Change Data and Detection Element. 


\section{References}

Charlson, R. J., S. E. Schwartz, J. M. Hales, R. D. Cess, J. A. Coakley, J. E. Hansen, and D. J. Hofmann, 1992: Climate forcing by anthropogenic aerosols. Science, 255, $423-430$

Chédin A., N. A. Scott, C. Wahiche, and P. Moulinier, 1985: The Improved Initialization Inversion Method: A High Resolution Physical Method for Temperature Retrievals from Satellites of the TIROS-N Series, J. Climate. Appl. Meteor., 24, $128-143$

Ellington, R. G., J. Ellis, and S. Fels, 1991: The intercomparison of radiation codes used in climate models: longwave results, J. Geophys. Res., 96, 8929-8953

Fu, Q. and K. N. Liou, 1993: Parameterization of the radiative properties of cirrus clouds, J. Atmos. Sci., 50, 2008-2025

Hahn, C. J., W. B. Rossow, and S. G. Warren, 2001: ISCCP Cloud Properties Associated with Standard Cloud Types Identified in Individual Surface Observations, $J$. Climate, $14,11-28$

Hu, Y. X. and K. Stamnes, 1993: An accurate parameterization of the radiative properties of water clouds suitable for use in climate models, J. Climate, 6, 728-742

Inoue, T., 1985: On the temperature and effect emissivity determination of semitransparent cirrus clouds by bispectral measurements in the $10 \mu \mathrm{m}$ window region. J. Meteorol. Soc. Jpn., 63, 88-98 
-, 1987: A cloud type classification with NOAA7 split-window measurements. $J$. Geophys. Res., 92, 3991-4000

—, 1989: Features of clouds over the tropical Pacific during northern hemispheric winter for split window measurements. J. Meteorol. Soc. Jpn., 67, 621-637

Jensen, E. J. and O. B. Toon, 1992: The potential effects of volcanic aerosols on cirrus cloud microphysics. Geophys. Res. Letters, 19, 1759-1762

Jensen, E. J., Owen B. Toon, Douglas L. Westphal, Stefan Kinne, and Andrew J. Heymsfield, 1994: Microphysical modeling of cirrus 2 . Sensitivity studies, $J$. Geophys. Res., 99, 10,443-10,454

Jin, Y., W. B. Rossow, and D. P. Wylie, 1996: Comparison of the climatologies of highlevel clouds from HIRS and ISCCP, J. Climate., 9, 2850-2879

—, and W. B. Rossow, 1997: Detection of cirrus overlapping low-level clouds. $J$. Geophys. Res., 102, 1727-1737

Key, J., Stremer user's guide, Tech. Rep. 96-01., Dep. Of Geogr., Boston Univ., Boston, Mass., 1996

Liou, K.N., 1986: Influence of cirrus clouds on weather and climate processes: A global perspective. Mon. Wea. Rev., 114, 1167-1199

McCormick, M. P., L. W. Thomason and C. R. Trepte, 1995: Atmospheric effects of the Mt Pinatubo eruption. Nature, 373, 399-404 
Parol, F., J. C. Buriez, G. Brogniez, and Y. Fouquart, 1991: Information content of AVHRR channel 4 and 5 with respect to the effective radius of cirrus cloud particles. J. Appl. Meteor., 30, 973-984

Pinto, J. O., J. A. Curry, and C. W. Fairall, 1997: Radiative characteristics of the Arctic atmosphere during spring as inferred from ground-based measurements. $J$. Geophys. Res., 102, 6941-6952.

Ramanathan, V., Eric J. Pitcher, Robert C. Malone, and Maurice L. Blackmon, 1983: The Response of a Spectral General Circulation Model to Refinement in Radiative Process, J. Atmos. Sci., 40, 605-630

Randall, David A., Harshvardhan, Donald A. Dazlich, and Thomas G. Corsetti, 1989: Interactions among Radiation, Convection, and Large-Scale Dynamics in a General Circulation Model, J. Atmos. Sci., 46, 1943-1970

Rossow, W. B., 1978: Cloud microphysics: analysis of the clouds of Earth, Venus, Mars, and Jupiter. Icarus, 36, 1-50

_, 1989: Measuring cloud properties from space: A review. J. Climate, 1, 75-86

-, and R. A. Schiffer, 1991: ISCCP cloud data products. Bull. Amer. Meteor. Soc., 72, 220

-, A. W. Walker, D. Beuschel, and M. Roiter, 1996: International Satellite Cloud Climatology Project (ISCCP) description of new cloud datasets. WMO/TD 737, World Climate Research Programme (ICSU and WMO), 115pp 
—, and R. A. Schiffer, 1999: Advances in understanding clouds from ISCCP. Bull. Amer. Meteor. Soc., 80, 2261-2287

Sassen, K., 1992: Evidence for liquid-phase cirrus cloud formation from volcanic aerosols: climatic implications. Science, 257, 516-519

-, D. O. Starr, G. G. Mace, M. R. Poellot, S. H. Melfi, W. L. Eberhard, J. D. Spinhirne, E. W. Eloranta, D. E. Hagen, and J. Hallett, 1995: The 5-6 December 1991 FIRE IFO II Jet streamer cirrus case study: possible influences of volcanic aerosols. $J$. Atmos. Sci., 52, 97-123

Schiffer, R. A., and W. B. Rossow, 1983: the International Satellite Cloud Climatology Project (ISCCP): the first project of the World Climate Research Programme. Bull. Amer. Meteor. Soc., 64, 779-784

Scott, N. A., A. Chédin, R. Armante, J. Francis, C. J. Stubenrauch, J.-P. Chaboureau, F. Chevallier, C. Claud, and F. Chéruy, 1999: Characteristics of of the TOVS Pathfinder Path-B Data set. Bull. Amer. Meteor. Soc., 80, 2679-2701.

Song, Naihui, David O'C. Starr, Donald J. Wuebbles, Allen Williams, and Susan M. Larson, 1996: Volcanic aerosols and interannual variation of high clouds, Geophys. Res. Letters, 23, 2657-2660

Stamnes, K., S. C. Tsay, W. Wiscombe and K. Jayaweera, 1988: Numerically stable algorithm for discrete-ordinate-method radiative transfer in multiple scattering and emitting layered media, Appl. Opt., 27, 2502-2509 
Stenchikov, G. L., I. Kirchner, A. Robock, H.-F. Graf, J. C. Antuna, R. G. Grainger, A. Lambert, and L. Thomason, 1998: Radiative forcing from the 1991 Mount Pinatubo volcanic eruption. J. Geophys. Res., 103, 13837-13857

Stephens, G. L., S.-C. Tsay, P. W. Stackhouse Jr., and P. J. Flatau, 1990: The relevance of the microphysical and radiative properties of cirrus clouds to climate and climate feedbacks. J. Atmos. Sci., 38, 235-247

Stubenrauch, C. J., N. A. Scott, and A. Chedin, 1996: Cloud Field Identification for Earth Radiation Budget Studies. Part I: Cloud Field Classification Using HIRS-MSU sounder Measurements, J. Appl. Meteor., 35, 416-427

-, W. B. Rossow, F. Cheruy, A. Chédin, and N. A. Scott, 1999a: Clouds as Seen by Satellite Sounders (3I) and Imagers (ISCCP). Part I: Evaluation of Cloud Parameters, J. Climate, 12, 2189-2213

—, A. Chédin, R. Armante, and N. A. Scott, 1999b: Clouds as Seen by Satellite Sounders (3I) and Imagers (ISCCP). Part II: A New Approach for Cloud Parameter Determination in the 3 I Algorithms, J. Climate, 12, 2214-2223

-, W. B. Rossow, N. A. Scott, and A. Chédin, 1999c: Clouds as Seen by Satellite Sounders (3I) and Imagers (ISCCP). Part III: Spatial Heterogeneity and Radiative Effects, J. Climate, 12, 3419-3442

-, and F. Eddounia, 2001: Cloud Property Survey from Satellite Observations using Vertical Sounders (TOVS Path-B) and Imagers (ISCCP), Workshop on IonAerosol-Cloud Interaction Proceed., CERN, Geneva 17 - 19 April 2001, 12 pp. 
Wu, M. C., 1987: A method for remote sensing the emissivity, fractional cloud cover, and cloud top temperature of high-level, thin clouds. J. Climate Appl. Meteor., 26, $225-233$

Wylie, D. P., W. P. Menzel, H. M. Woolf, and K. I. Strabala, 1994: Four years of global cirrus cloud statistics using HIRS. J. Climate, 7, 1972-1986

—, and W. P. Menzel, 1999: Eight years of high cloud statistics using HIRS. J. Climate, $12,170-184$ 


\section{Figure Captions}

Fig. 1. Cloud classification in split-window method. a) The original classification; b) the modified classification used in this study.

Fig. 2. Cloud-type classification in the ISCCP D-series datasets.

Fig. 3. Simulated satellite observed brightness temperature difference (BTD) for different cloud types as defined in ISCCP. The upper panel assumes all clouds are ice clouds; the middle panel assumes all clouds are water clouds; the lower panel combine both by assuming clouds above $440 \mathrm{mb}$ are ice clouds and clouds below are water clouds. Satellite zenith angle is $0^{0}$ (nadir).

Fig. 4. The same as figure 4, except that satellite zenith angle is $60^{\circ}$.

Fig. 5. Simulated satellite observed clear-sky brightness temperature difference (BTD) as a function of satellite zenith angle. The tropical profile is used.

Fig. 6. Simulation of cloud types classified by the split-window method in the Pc-Tau space. The upper panel assumes nadir viewing; the lower panel assume $60^{\circ}$ satellite zenith angle. Dashed lines correspond to the ISCCP cloud-type classification (see Fig 2).

Fig. 7. Deviations of global (except polar regions) monthly mean cirrus and cumulus cloud amount (\%) derived from the ISCCP. Only clouds over ocean are shown. A longer series can be found in the paper by Rossow and Shiffer (1999).

Fig. 8. The evolution of the stratospheric aerosol extinction at $1.02 \mu \mathrm{m}$ derived from SAGE II. 
Fig. 9. Zonal mean cloud amount anomalies of various types as a function of latitude and time derived from the ISCCP and the split-window observations. Only clouds over ocean are considered.

Fig. 10. The same as Fig. 9, except that it is for clouds over land only.

Fig. 11a, 11b. Cirrus cloud amount anomalies with time from the ISCCP and $3 I$ dataset.

Fig. 12. Zonal mean BTD anomalies as a function of latitude and time derived from the ISCCP.

Fig. 13. The same as figure 12, except that they are derived from the split-window method. Also, BTD for clear sky is also shown.

\section{Table captions}

Table 1. Cloud amount distribution of each cloud type classified by the ISCCP (horizontal) as a function of the classification by the split-window method (vertical). The table is for warm pool oceanic areas. Note that sometimes the total cloud amount is different from the sum of the corresponding row or column by about 1 , because we round every cloud amount (which is a real number) to an integer and also do the same to the total cloud amount.

Table 2. The same as table 1, except that it is for African tropical land. 
(a) The original split-window cloud classification algorithm by Inoue

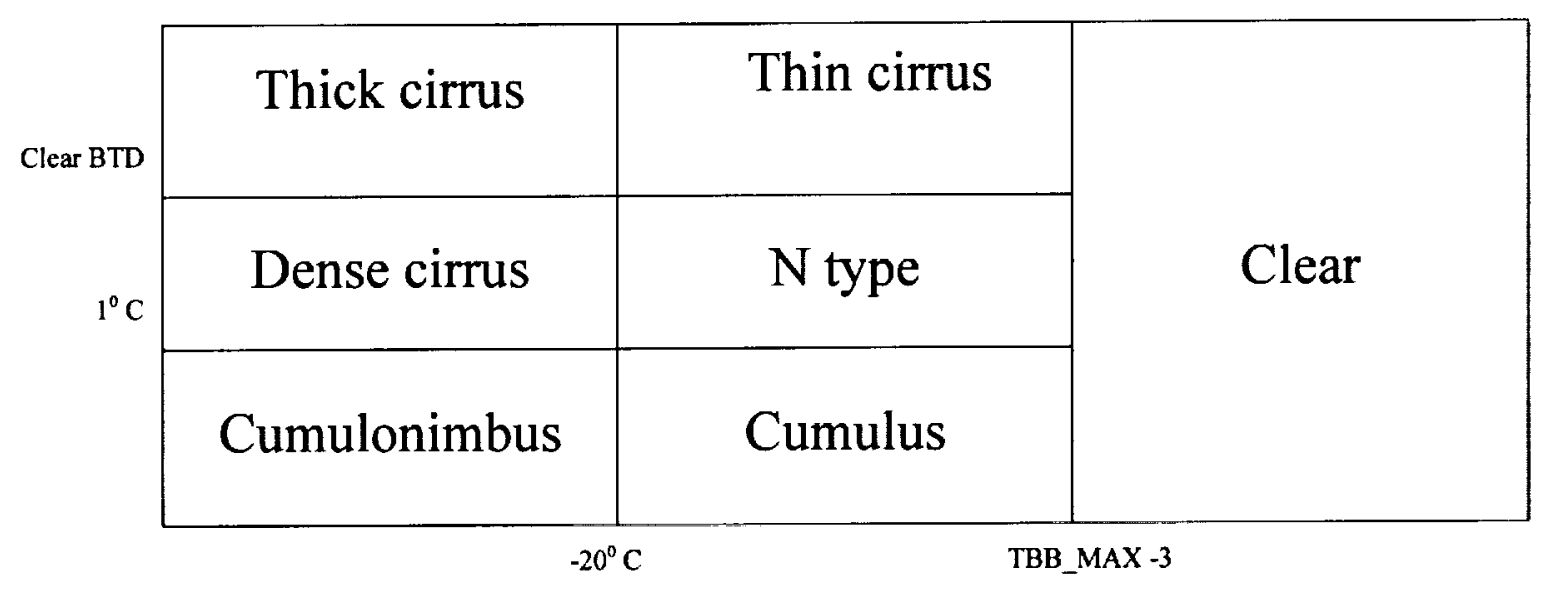

(b) The modified version of split-window cloud classification algorithm

\begin{tabular}{|c|c|c|}
\hline Thick cirrus & Thin cirrus & \multirow{2}{*}{ Clear } \\
\cline { 1 - 3 } Clear BTD & N type \\
\hline Cumulonimbus & Cumulus \\
\hline \multicolumn{2}{|c|}{ temperature at $440 \mathrm{mbar}$} \\
\hline
\end{tabular}


ISCCP CLOUD CLASSIFICATION

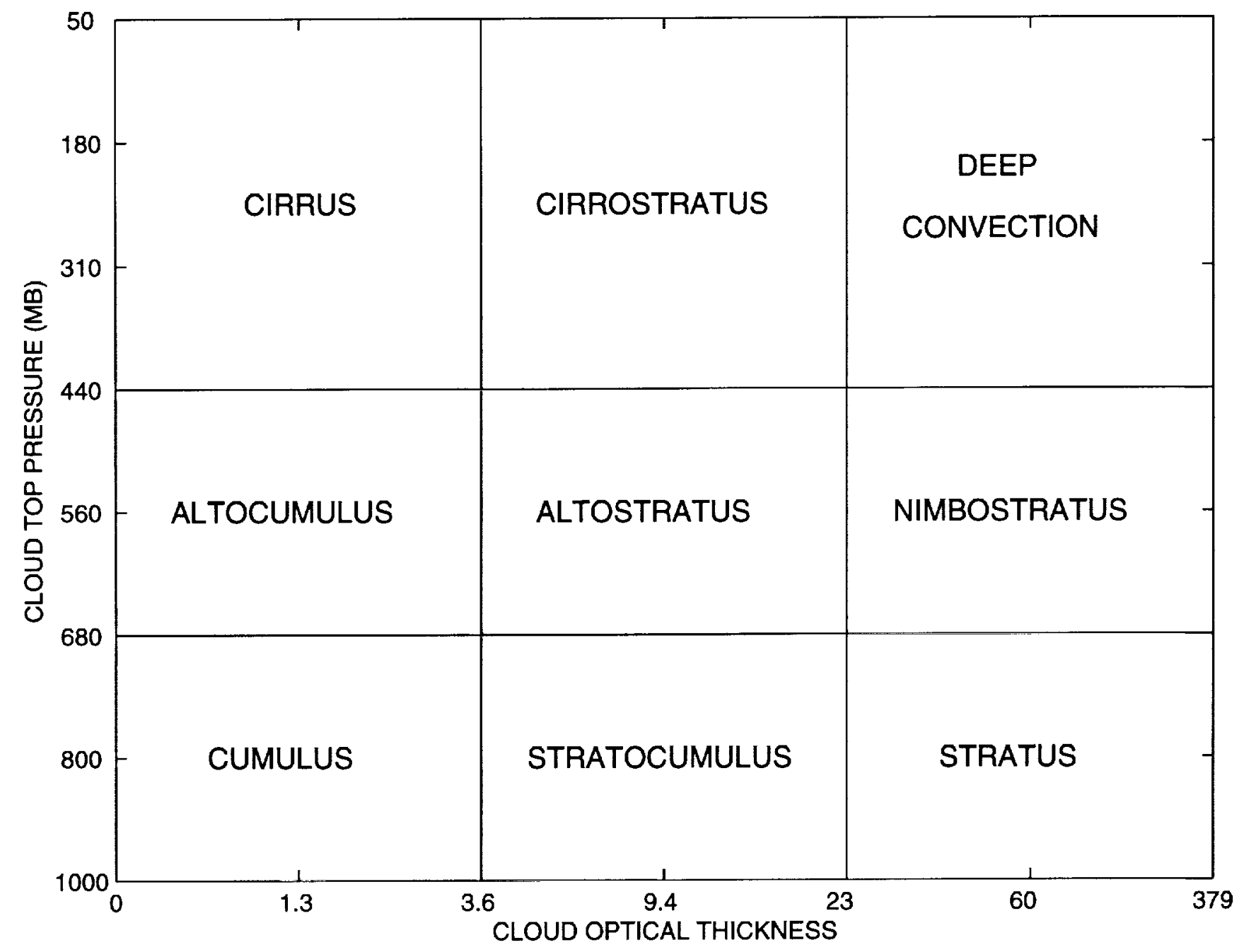

Fig 2 


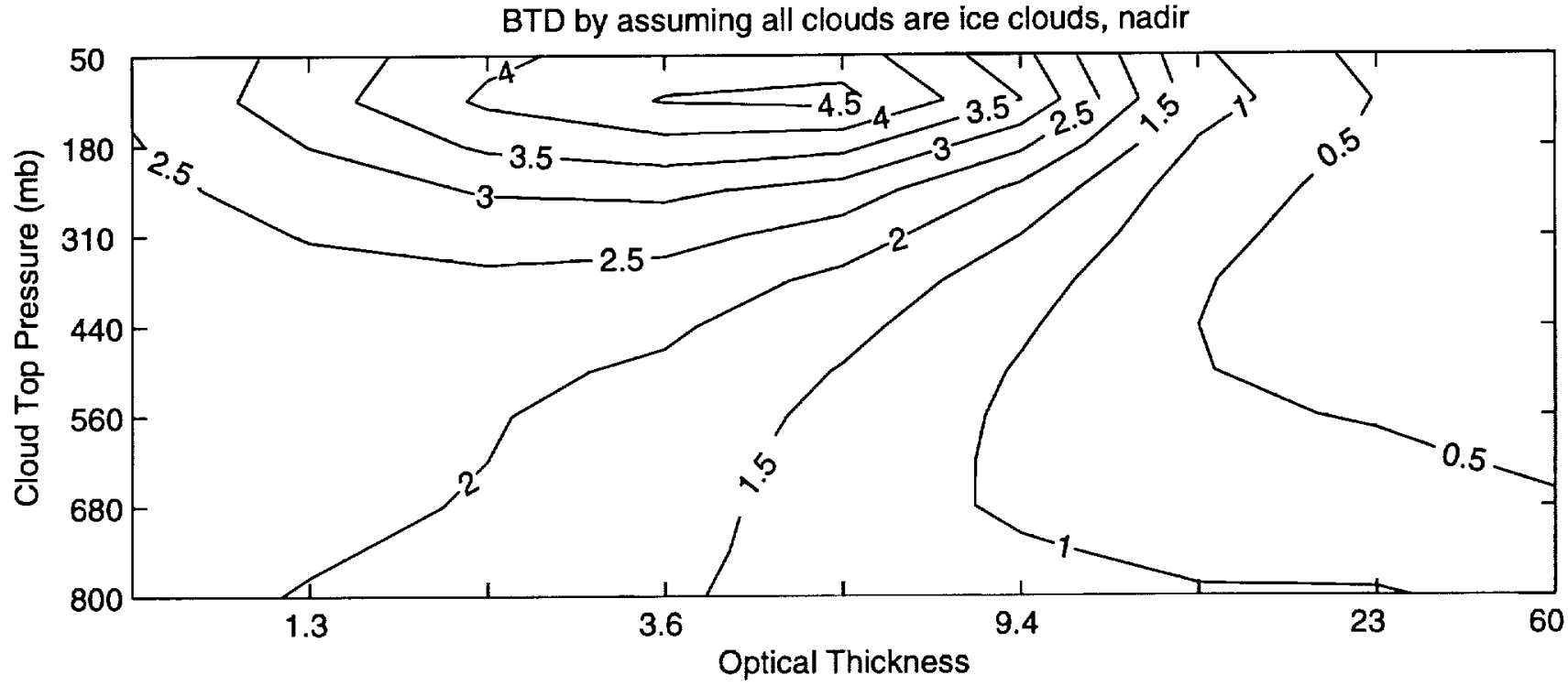

BTD by assuming all clouds are water clouds, nadir

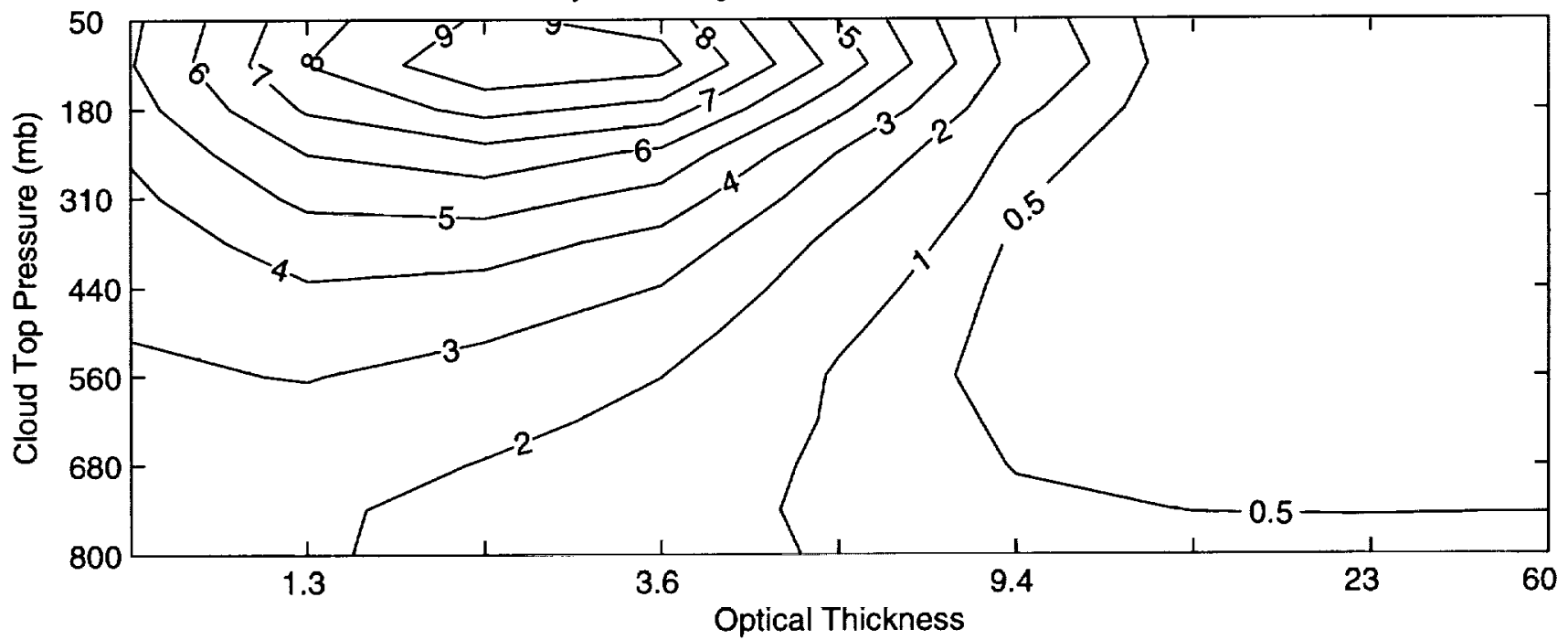

BTD by assuming clouds above $440 \mathrm{mb}$ are ice clouds and clouds below are water clouds, nadir

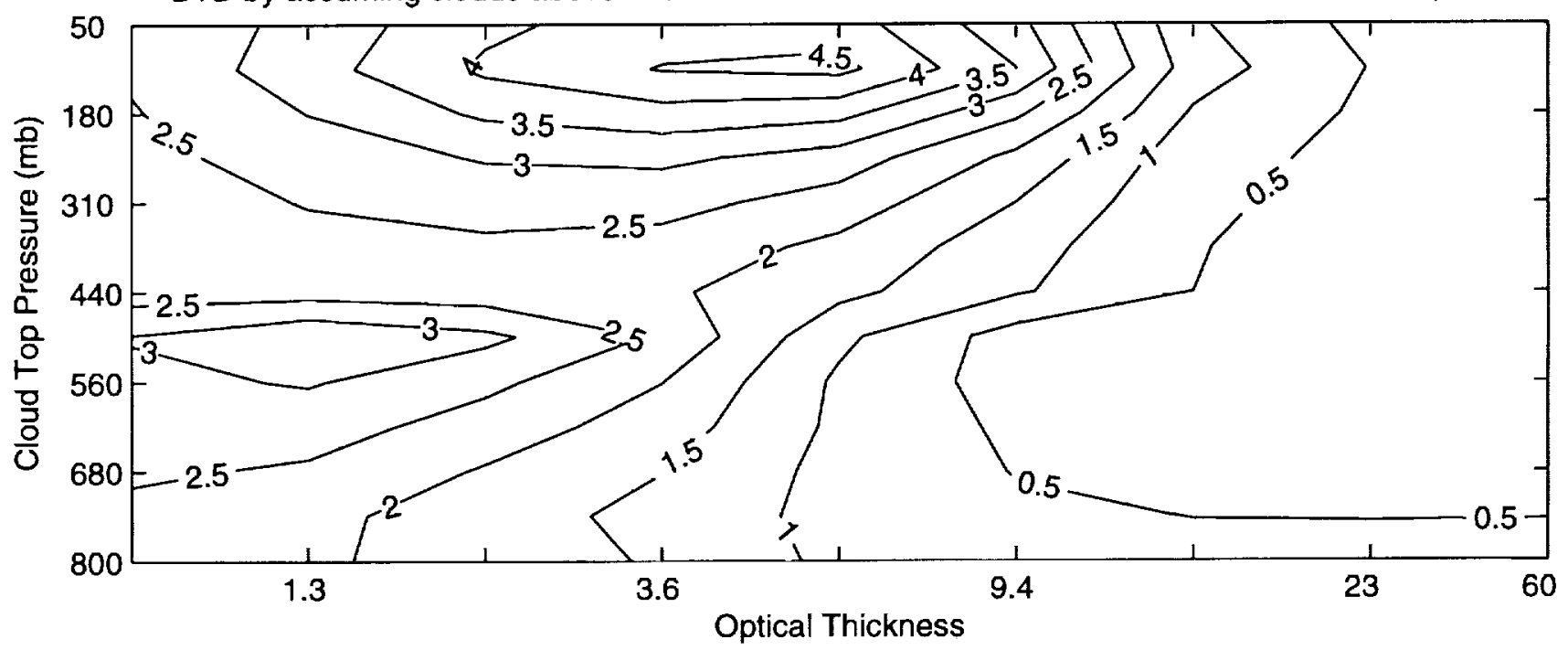

Fig 3 

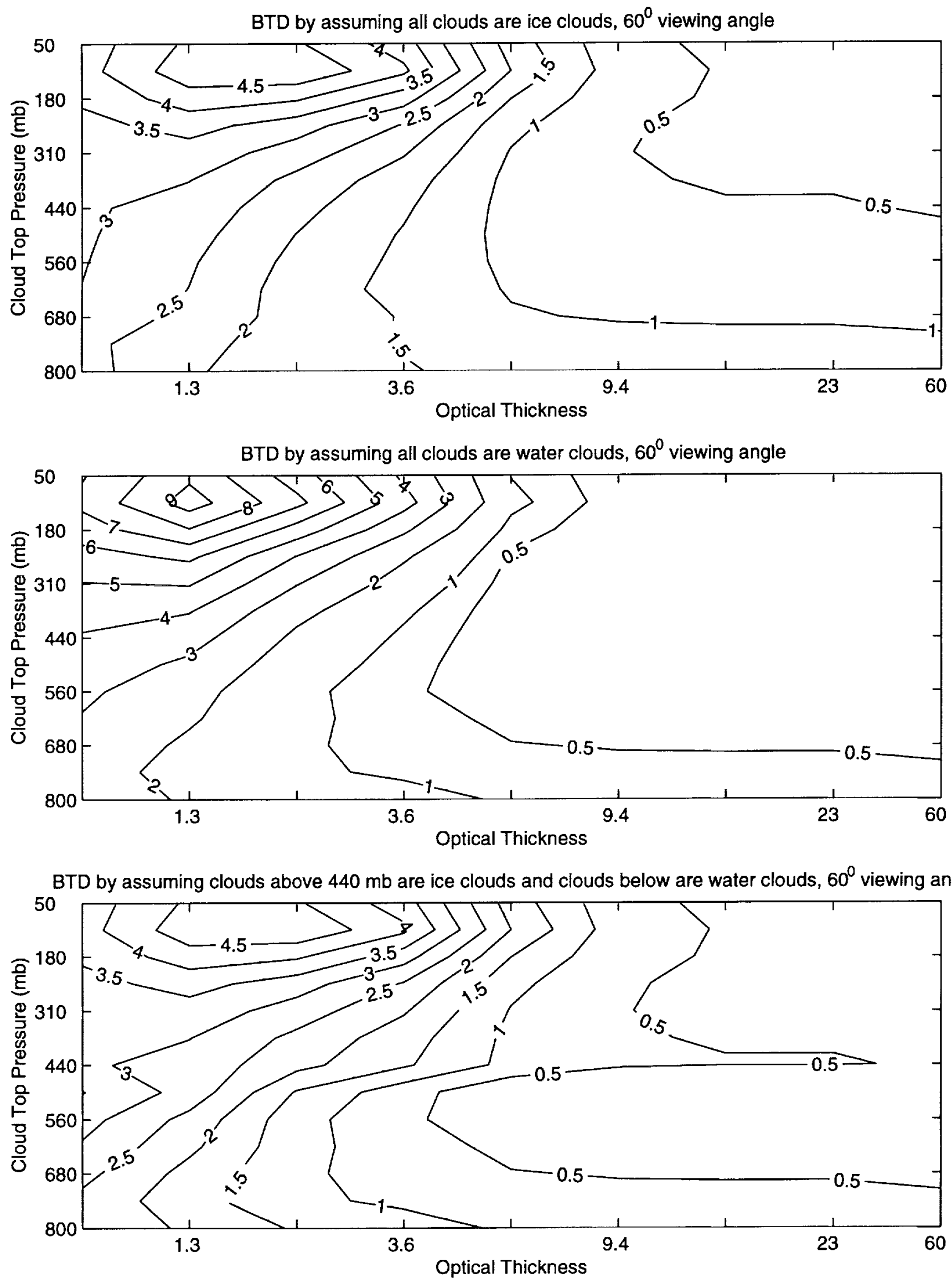


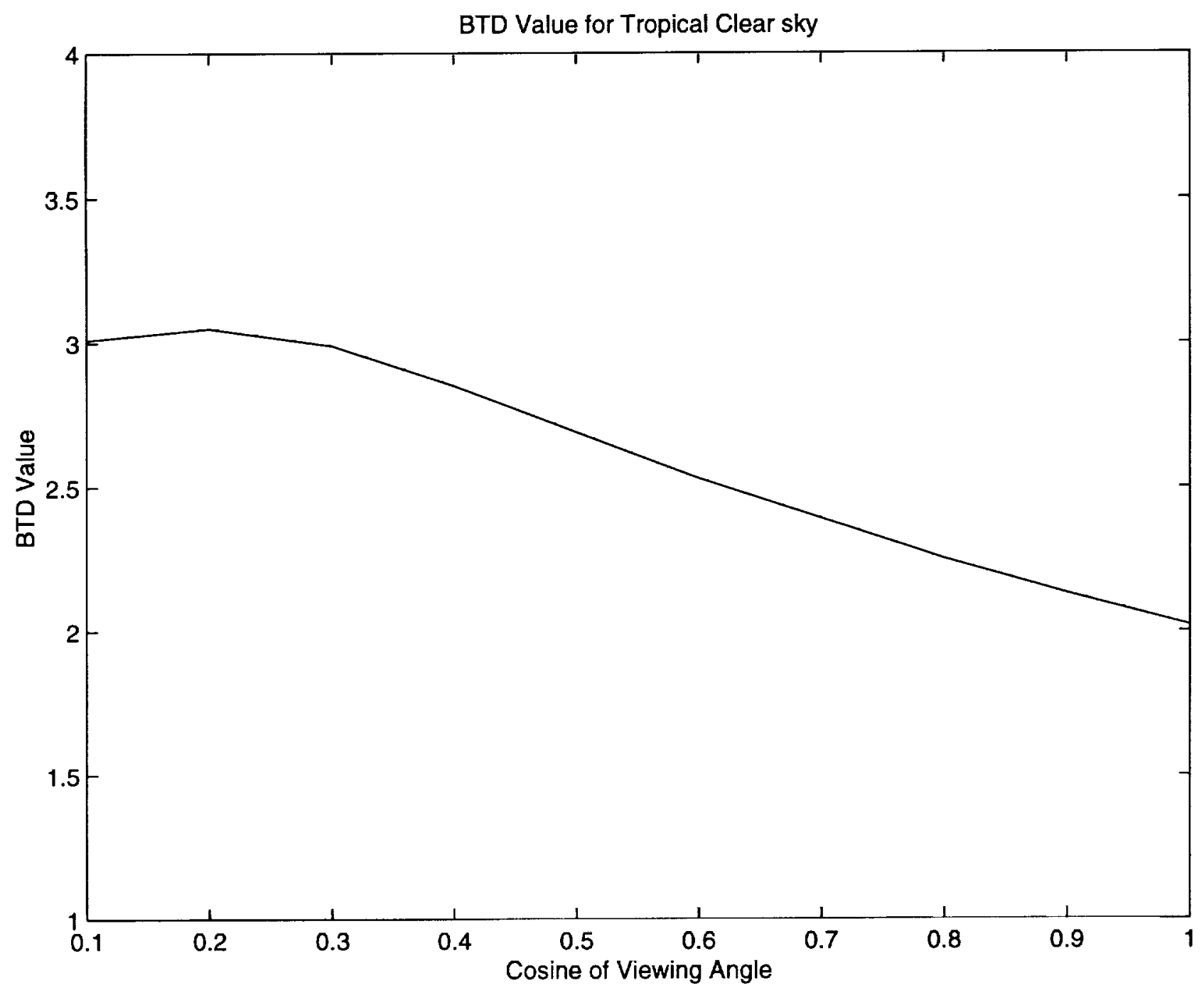

Fig 5 

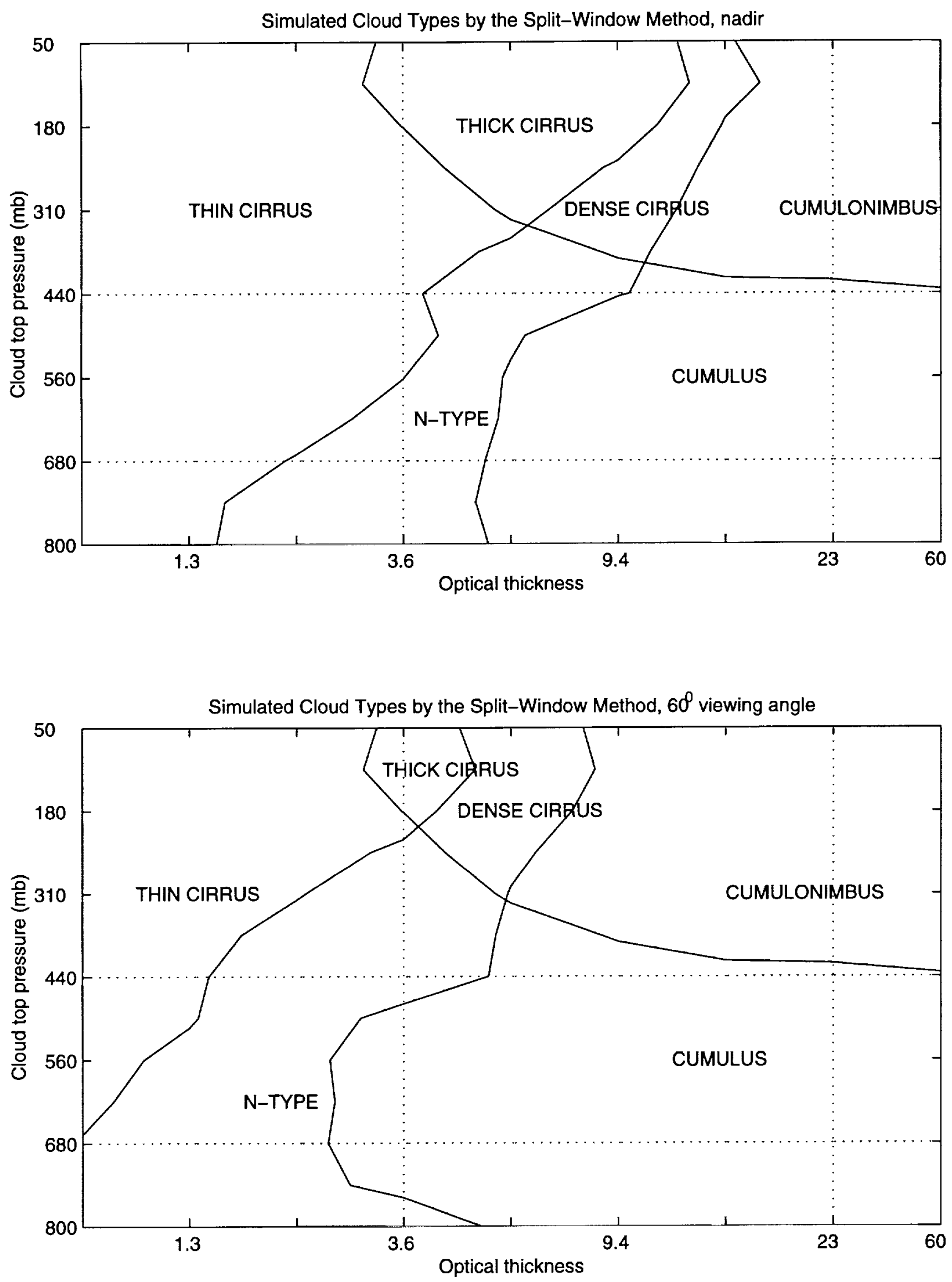


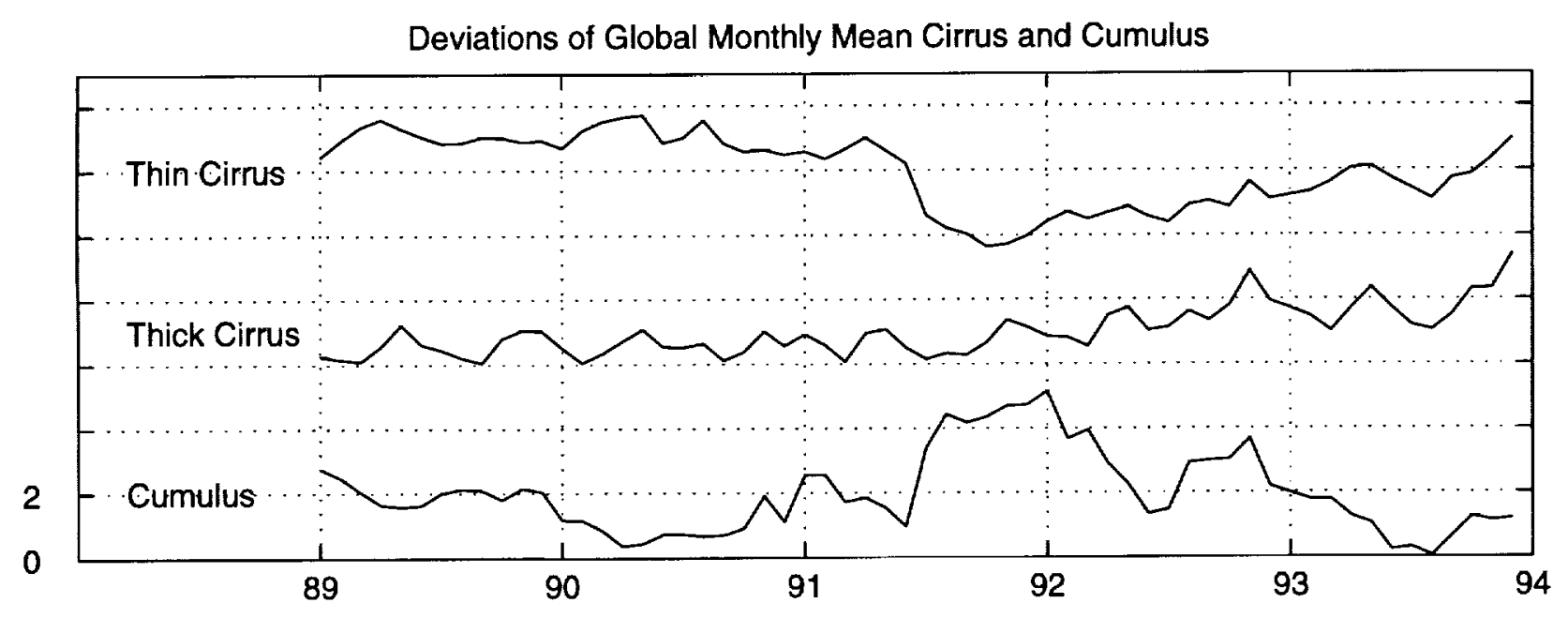

Fig 7 


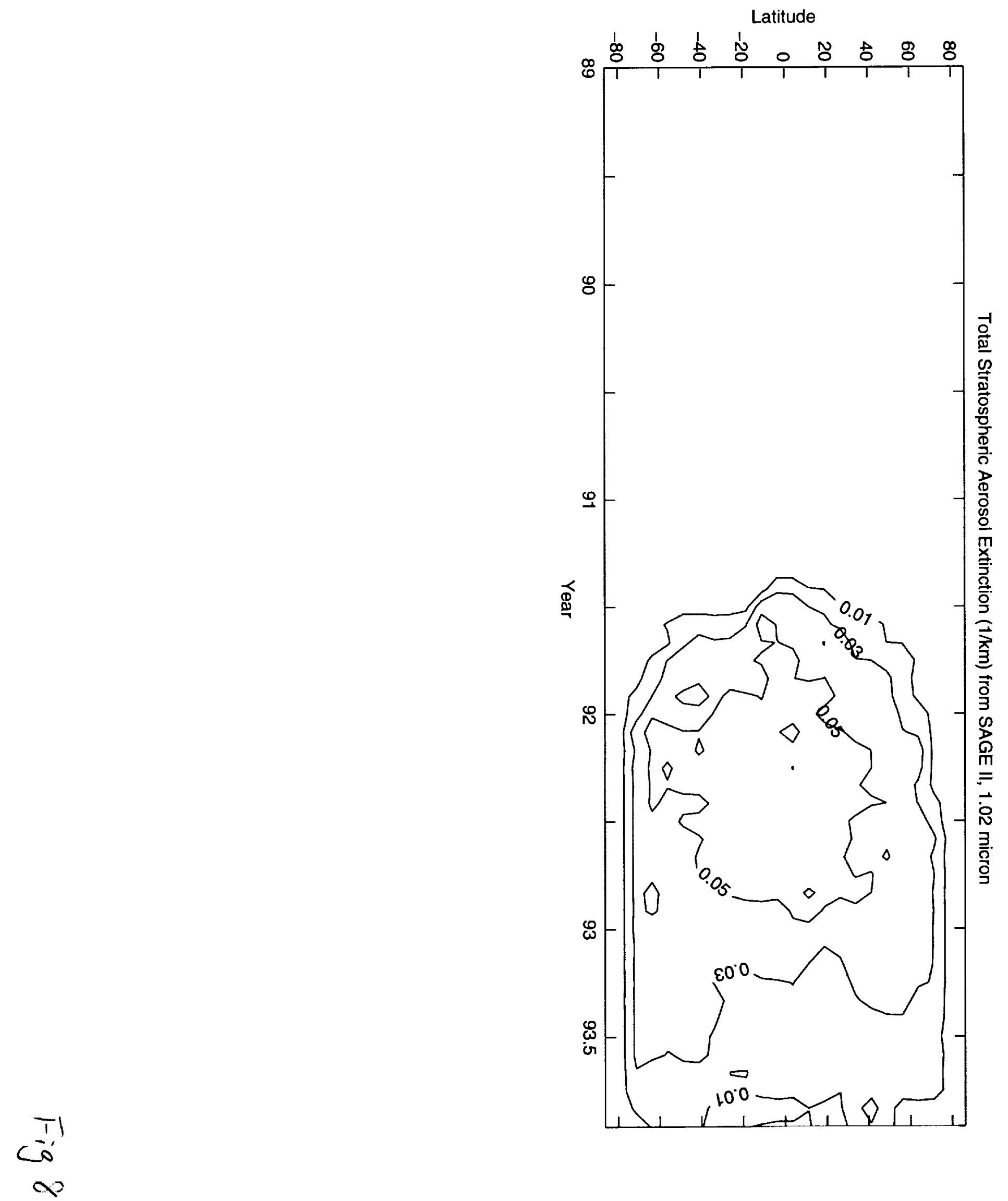


Latitude

Latitude

Latitude

Latitude
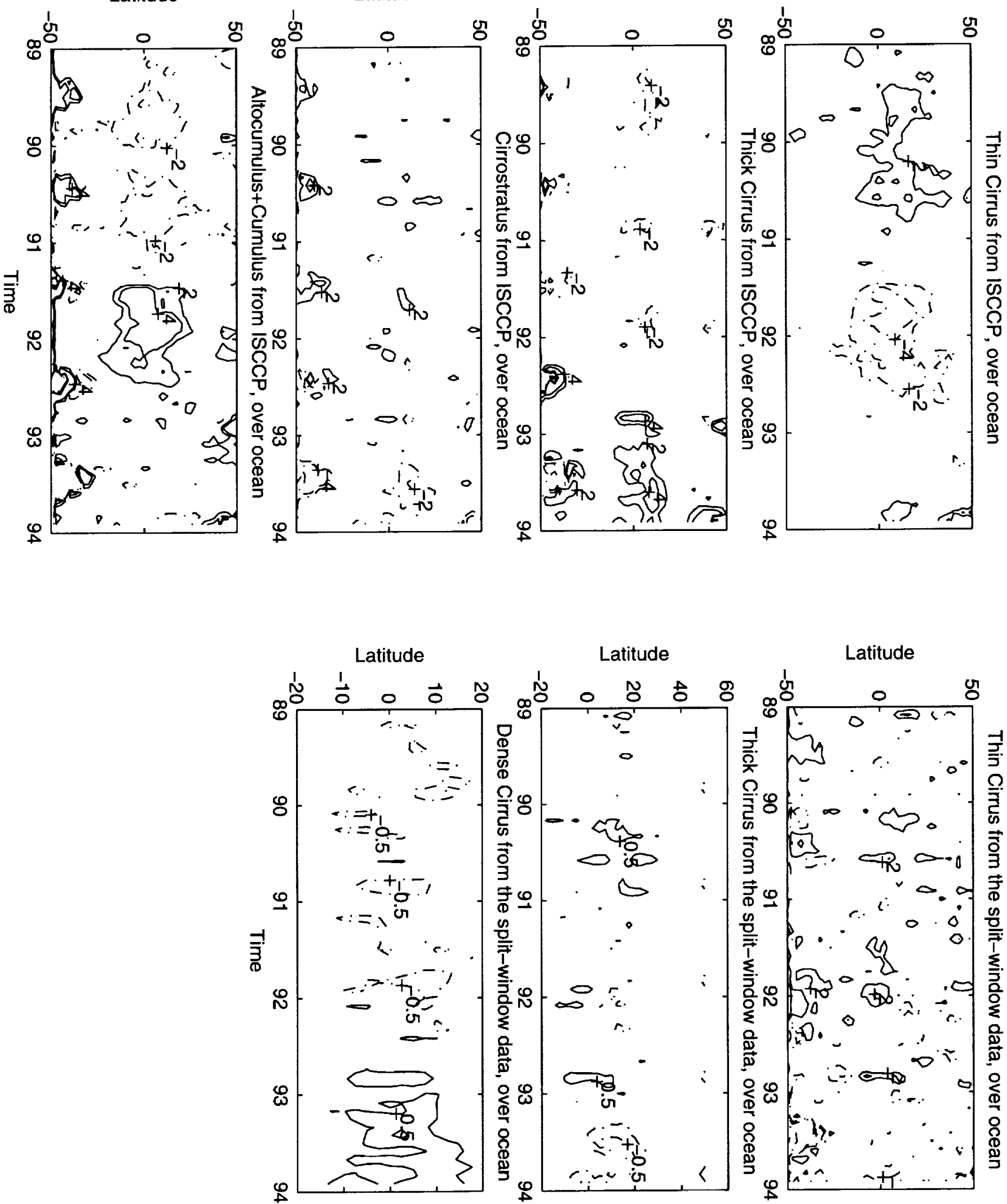

T) 
Latitude

Latitude

Latitude

Latitude
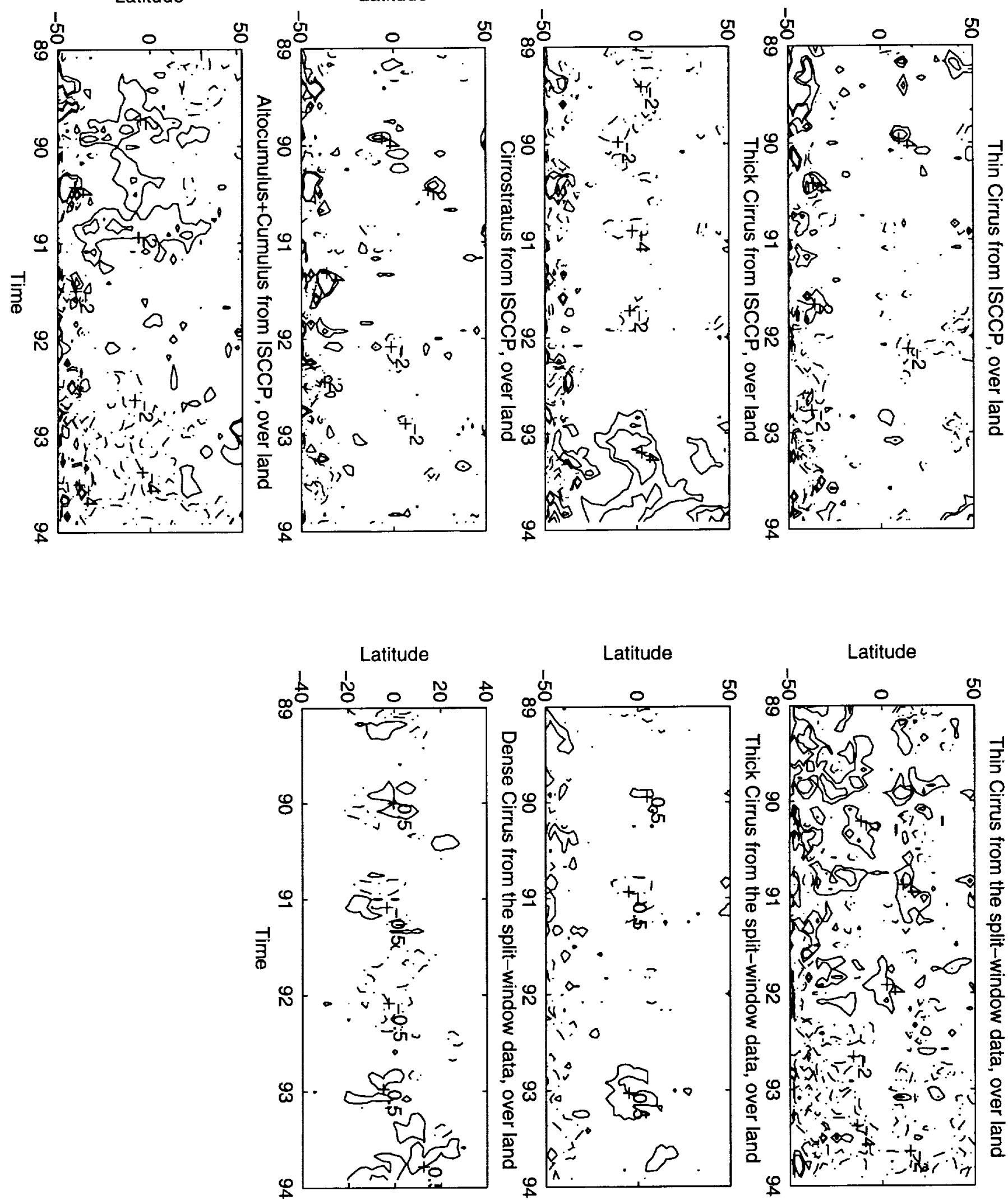

$\frac{\pi}{0}$ 

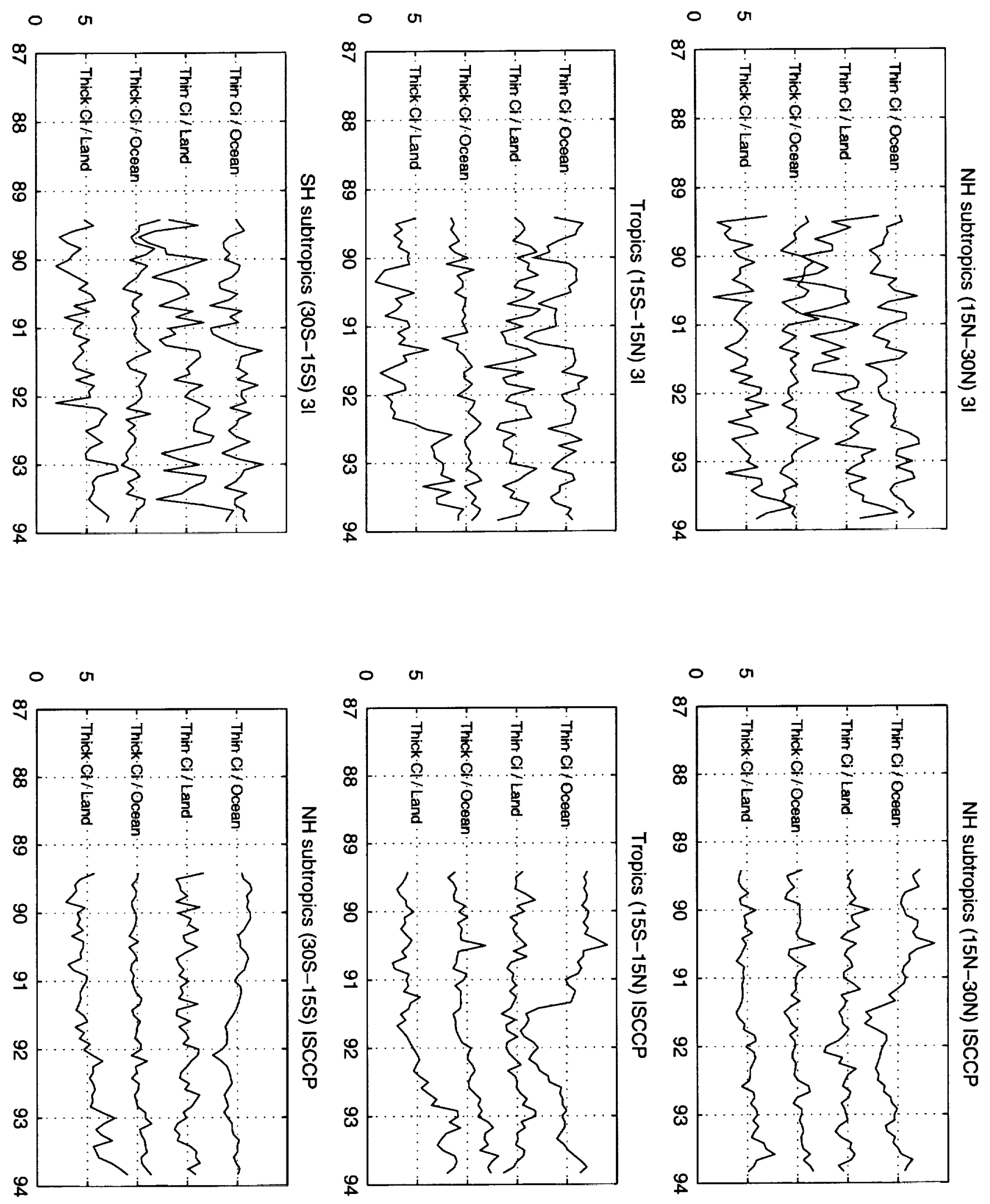

$\frac{11}{8}$ 

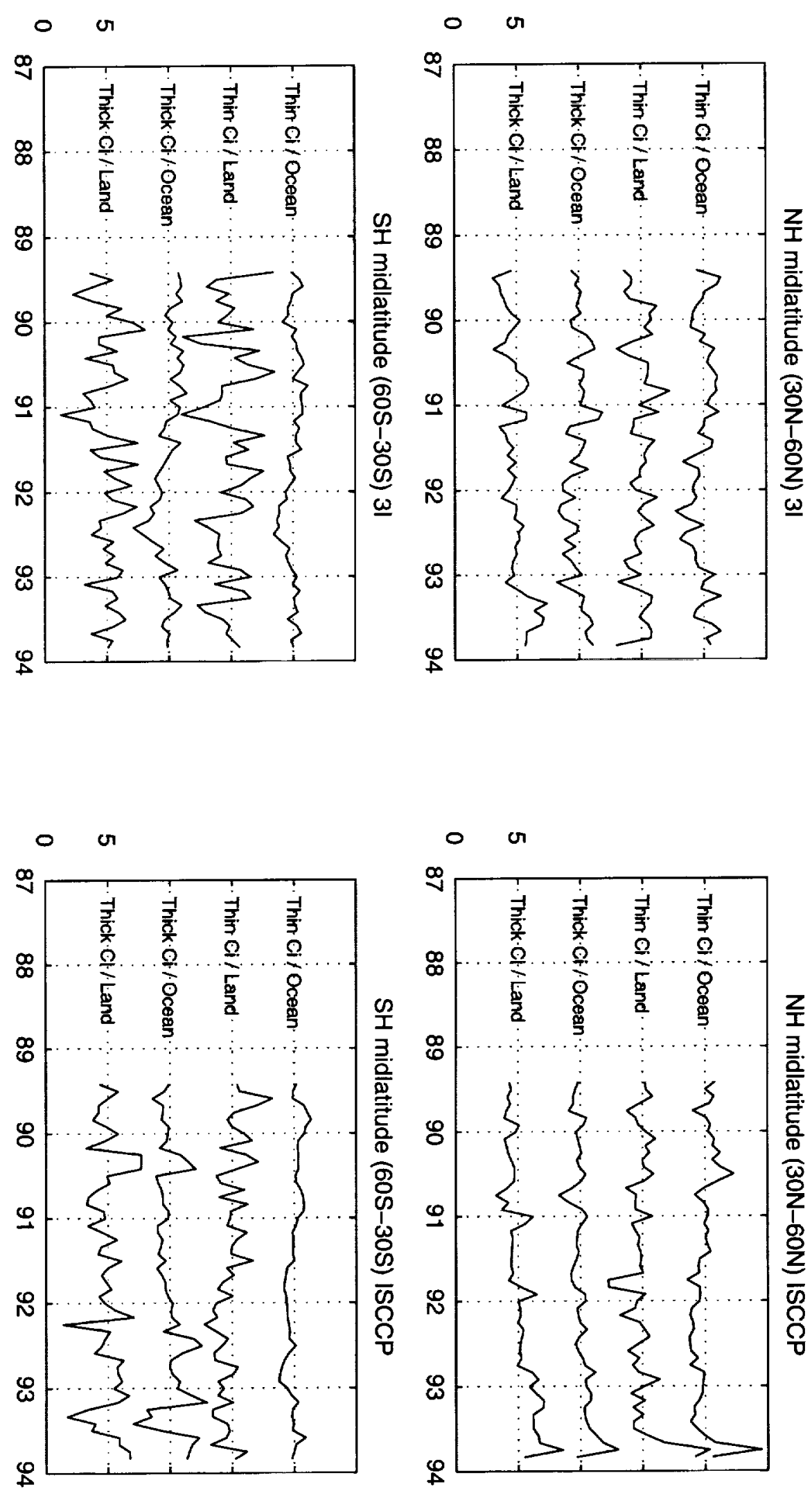

$\stackrel{\bar{\sigma}}{\bar{\sigma}}$ 
Latitude

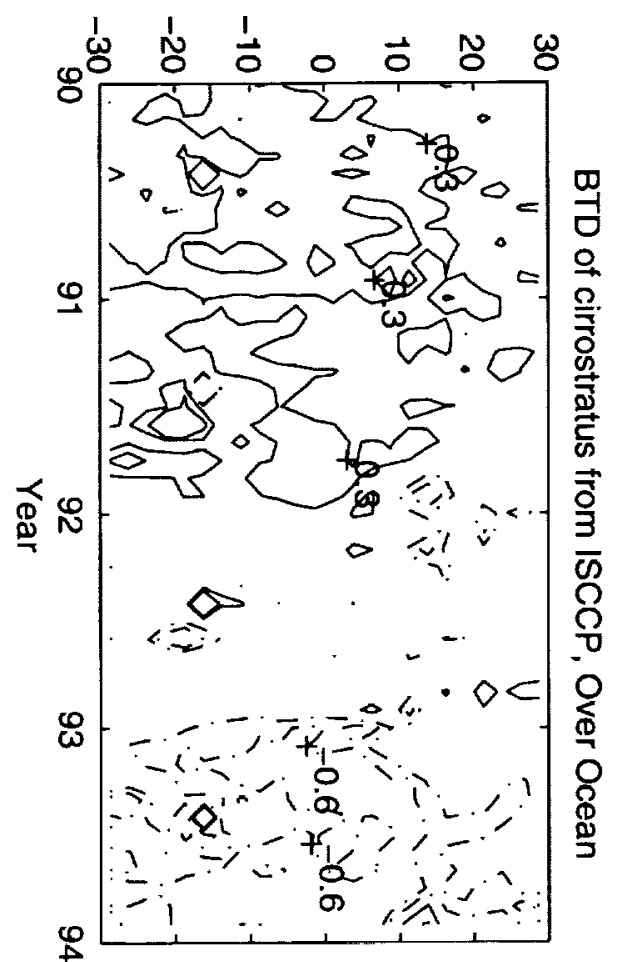

Latitude

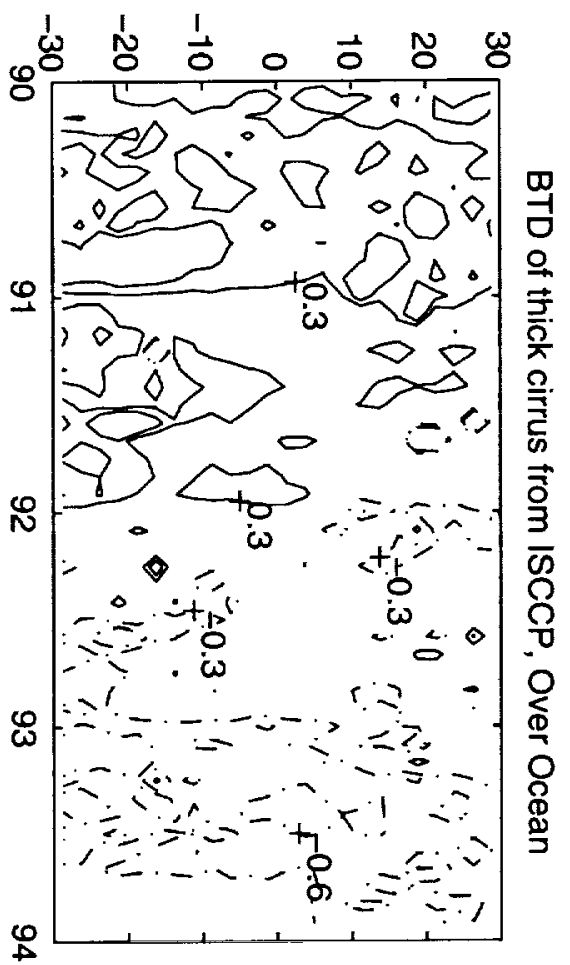

Latitude

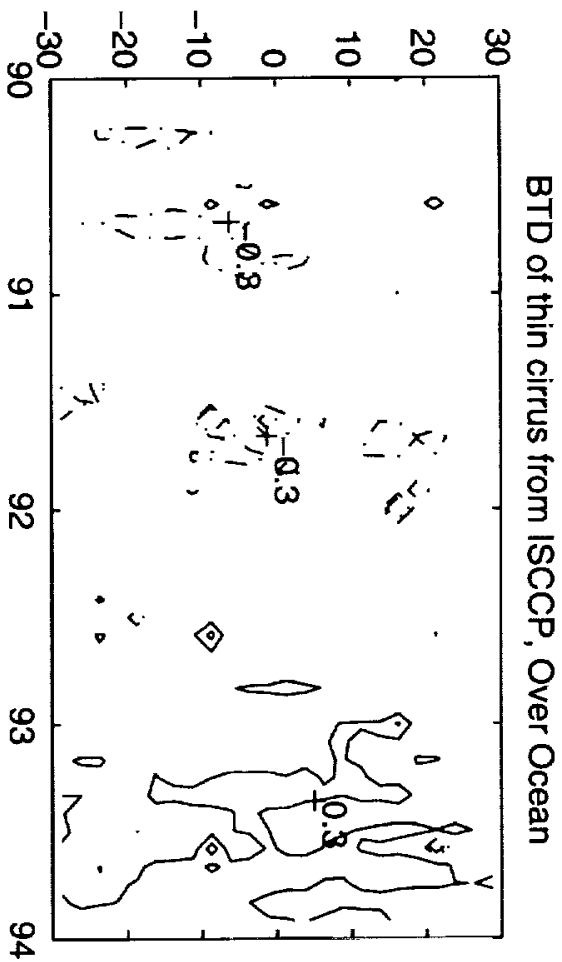

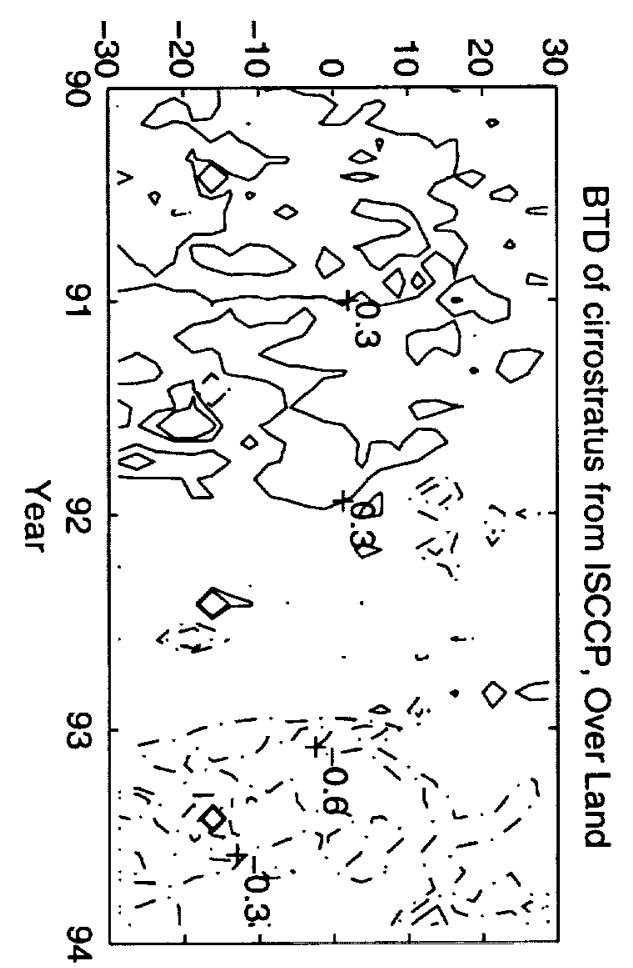
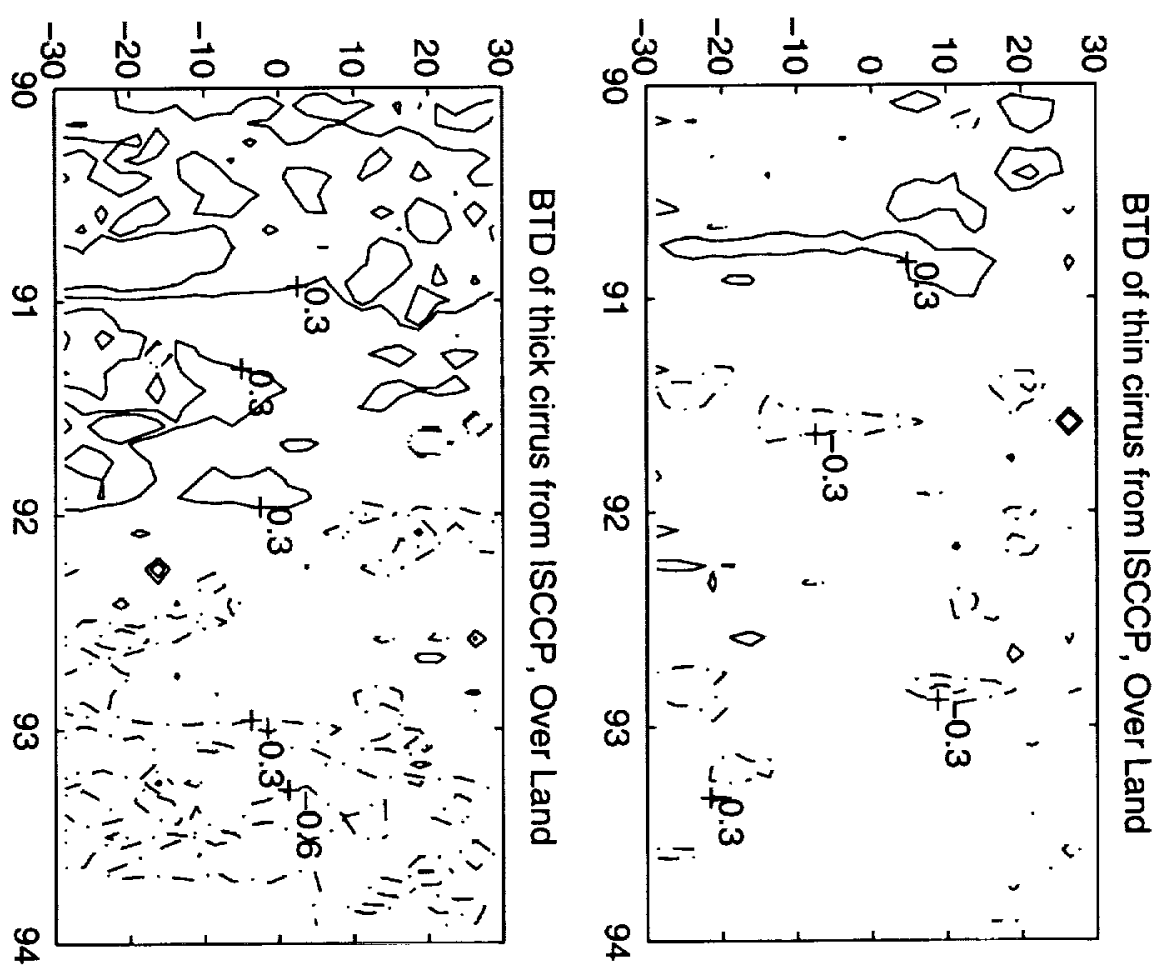

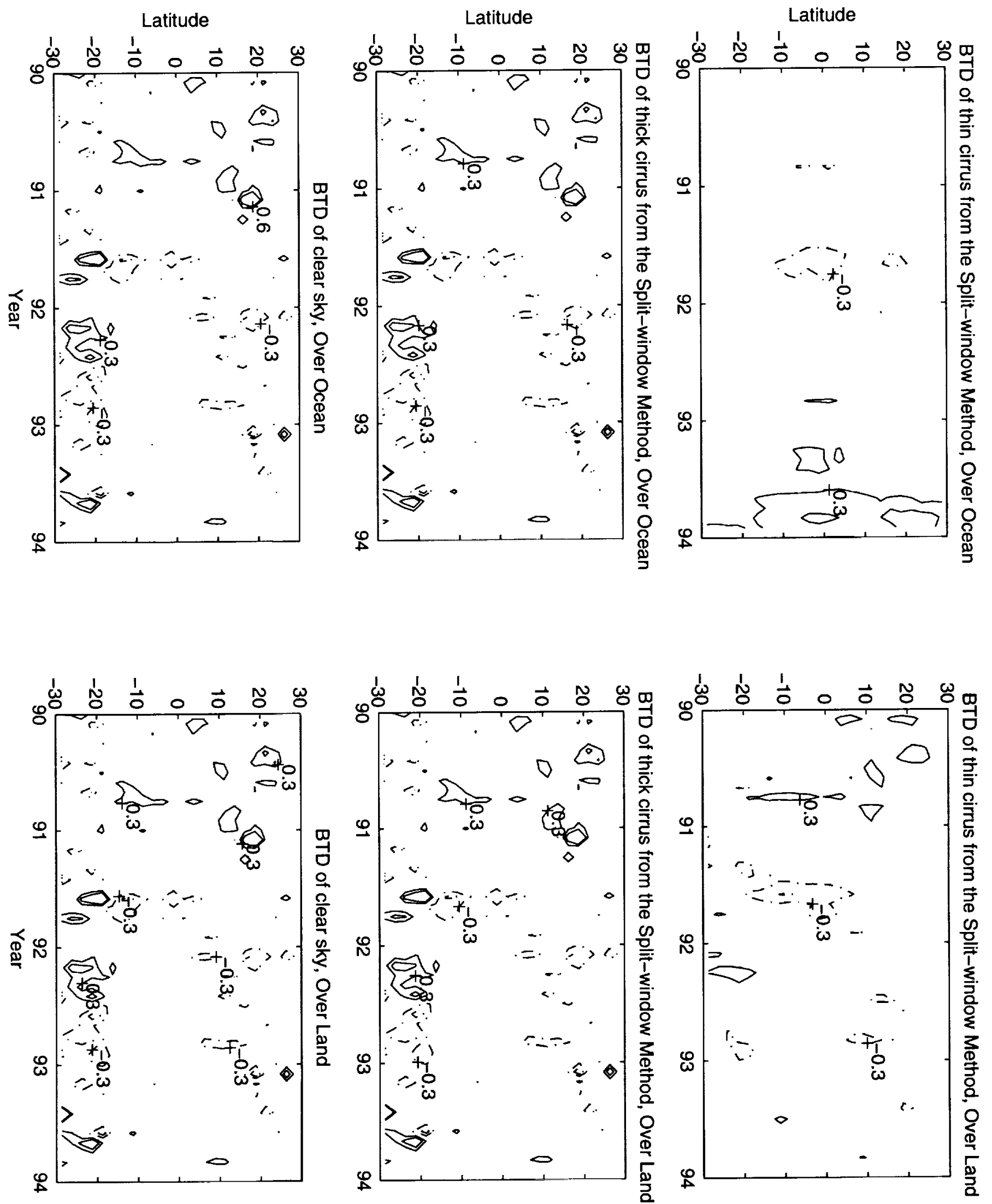

II 
Warm Pool Ocean: 15S-15N;100E-150E, 9001

\begin{tabular}{|c|c|c|c|c|c|c|c|c|c|c|c|c|}
\hline & thin ci & thick ci & $\begin{array}{l}\text { cirro- } \\
\text { stratus }\end{array}$ & $\begin{array}{l}\text { deep } \\
\text { convection }\end{array}$ & $\begin{array}{l}\text { alto- } \\
\text { cumulus }\end{array}$ & $\begin{array}{l}\text { alto- } \\
\text { stratus }\end{array}$ & $\begin{array}{l}\text { nimbo- } \\
\text { stratus }\end{array}$ & cumulus & $\begin{array}{l}\text { strato- } \\
\text { cumulus }\end{array}$ & stratus & clear & total \\
\hline thin ci & 11 & 4 & 0 & 0 & 8 & 2 & 0 & 3 & 1 & 0 & 0 & 29 \\
\hline thick ci & 0 & 4 & 1 & 0 & 0 & 0 & 0 & 0 & 0 & 0 & 0 & 5 \\
\hline dense ci & 0 & 3 & 2 & 0 & 0 & 0 & 0 & 0 & 0 & 0 & 0 & 5 \\
\hline N-type & 1 & 1 & 0 & 0 & 1 & 3 & 0 & 2 & 2 & 0 & 0 & 10 \\
\hline \begin{tabular}{|l|} 
cumulo- \\
nimbus
\end{tabular} & 0 & 2 & 15 & 8 & 0 & 0 & 0 & 0 & 0 & 0 & 0 & 24 \\
\hline cumulus & 0 & 0 & 0 & 0 & 0 & 1 & 0 & 0 & 1 & 0 & 0 & 4 \\
\hline clear & 0 & 0 & 0 & 0 & 0 & 0 & 0 & 0 & 0 & 0 & 23 & 23 \\
\hline total & 12 & 14 & 18 & 8 & 9 & 7 & 1 & 5 & 4 & 0 & 23 & 100 \\
\hline
\end{tabular}

Warm Pool Ocean: 15S-15N;100E-150E, 9007

\begin{tabular}{|c|c|c|c|c|c|c|c|c|c|c|c|c|}
\hline & thin $\mathrm{ci}$ & thick ci & $\begin{array}{l}\text { cirro- } \\
\text { stratus }\end{array}$ & \begin{tabular}{|l} 
deep \\
convection
\end{tabular} & \begin{tabular}{|l|} 
alto- \\
cumulus
\end{tabular} & $\begin{array}{l}\text { alto- } \\
\text { stratus }\end{array}$ & $\begin{array}{l}\text { nimbo- } \\
\text { stratus }\end{array}$ & cumulus & $\begin{array}{l}\text { strato- } \\
\text { cumulus }\end{array}$ & stratus & clear & total \\
\hline thin $\mathrm{ci}$ & 11 & 3 & 0 & 0 & 5 & 1 & 0 & 3 & 1 & 0 & 0 & 23 \\
\hline thick ci & 0 & 2 & 0 & 0 & 0 & 0 & 0 & 0 & 0 & 0 & 0 & 3 \\
\hline dense ci & 0 & 2 & 1 & 0 & 0 & 0 & 0 & 0 & 0 & 0 & 0 & 3 \\
\hline N-type & 1 & 1 & 0 & 0 & 1 & 2 & 0 & 2 & 2 & 0 & 0 & 9 \\
\hline $\begin{array}{l}\text { cumulo- } \\
\text { nimbus }\end{array}$ & 0 & 2 & 10 & 5 & 0 & 0 & 0 & 0 & 0 & 0 & 0 & 17 \\
\hline cumulus & 0 & 0 & 0 & 0 & 0 & 2 & 0 & 1 & 2 & 0 & 0 & 6 \\
\hline clear & 0 & 0 & 0 & 0 & 0 & 0 & 0 & 0 & 0 & 0 & 40 & 40 \\
\hline total & 12 & 10 & 11 & 5 & 6 & 5 & 0 & 6 & 5 & 0 & 40 & 100 \\
\hline
\end{tabular}


African Tropical Land: 15S-0; 10E-50E, 9001

\begin{tabular}{|c|c|c|c|c|c|c|c|c|c|c|c|c|}
\hline & thin $\mathrm{ci}$ & thick ci & $\begin{array}{l}\text { cirro- } \\
\text { stratus }\end{array}$ & $\begin{array}{l}\text { deep } \\
\text { convection }\end{array}$ & $\left|\begin{array}{l}\text { alto- } \\
\text { cumulus }\end{array}\right|$ & $\begin{array}{l}\text { alto- } \\
\text { stratus }\end{array}$ & $\begin{array}{l}\text { nimbo- } \\
\text { stratus }\end{array}$ & cumulus & \begin{tabular}{|l|} 
strato- \\
cumulus
\end{tabular} & stratus & clear & total \\
\hline thin ci & 6 & 1 & 0 & 0 & 5 & 1 & 0 & 3 & 1 & 0 & 0 & 17 \\
\hline thick ci & 0 & 1 & 0 & 0 & 0 & 0 & 0 & 0 & 0 & 0 & 0 & 2 \\
\hline dense ci & 0 & 3 & 1 & 0 & 0 & 0 & 0 & 0 & 0 & 0 & 0 & 4 \\
\hline N-type & 4 & 1 & 0 & 0 & 4 & 6 & 0 & 4 & 4 & 0 & 0 & 22 \\
\hline \begin{tabular}{|l|} 
cumulo- \\
nimbus
\end{tabular} & 0 & 2 & 14 & 9 & 0 & 0 & 0 & 0 & 0 & 0 & 0 & 25 \\
\hline cumulus & 0 & 0 & 0 & 0 & 0 & 4 & 2 & 0 & 0 & 0 & 0 & 7 \\
\hline clear & 0 & 0 & 0 & 0 & 0 & 0 & 0 & 0 & 0 & 0 & 23 & 23 \\
\hline total & 10 & 8 & 16 & 9 & 9 & 10 & 2 & 7 & 5 & 0 & 23 & 100 \\
\hline
\end{tabular}

African Tropical Land: 15S-0; 10E-50E, 9007

\begin{tabular}{|c|c|c|c|c|c|c|c|c|c|c|c|c|}
\hline & thin ci & thick ci & $\begin{array}{l}\text { cirro- } \\
\text { stratus }\end{array}$ & $\begin{array}{l}\text { deep } \\
\text { convection }\end{array}$ & $\begin{array}{l}\text { alto- } \\
\text { cumulus }\end{array}$ & $\begin{array}{l}\text { alto- } \\
\text { stratus }\end{array}$ & $\begin{array}{l}\text { nimbo- } \\
\text { stratus }\end{array}$ & cumulus & $\begin{array}{l}\text { strato- } \\
\text { cumulus }\end{array}$ & stratus & clear & total \\
\hline thin ci & 5 & 0 & 0 & 0 & 5 & 1 & 0 & 4 & 3 & 0 & 0 & 18 \\
\hline thick ci & 0 & 0 & 0 & 0 & 0 & 0 & 0 & 0 & 0 & 0 & 0 & 1 \\
\hline dense ci & 0 & 0 & 0 & 0 & 0 & 0 & 0 & 0 & 0 & 0 & 0 & 0 \\
\hline N-type & 1 & 0 & 0 & 0 & 1 & 1 & 0 & 1 & 2 & 0 & 0 & 7 \\
\hline $\begin{array}{l}\text { cumulo- } \\
\text { nimbus }\end{array}$ & 0 & 0 & 1 & 0 & 0 & 0 & 0 & 0 & 0 & 0 & 0 & 2 \\
\hline cumulus & 2 & 0 & 0 & 0 & 3 & 2 & 2 & 1 & 4 & 0 & 0 & 14 \\
\hline clear & 0 & 0 & 0 & 0 & 0 & 0 & 0 & 0 & 0 & 0 & 58 & 58 \\
\hline total & 8 & 2 & 1 & 0 & 9 & 5 & 2 & 7 & 9 & 0 & 58 & 100 \\
\hline
\end{tabular}

